\title{
Strategies towards chiral molecular conductors
}

\author{
Narcis Avarvari*a and John D. Wallis*b
}

${ }^{a}$ Université d'Angers, CNRS, Laboratoire de Chimie et Ingénierie Moléculaire, CIMA UMR 6200, UFR Sciences, Bât. K, 2 Bd. Lavoisier, 49045 Angers, France. E-mail: narcis.avarvari@univ-angers.fr

${ }^{\mathrm{b}}$ School of Science and Technology, Nottingham Trent University, Clifton Lane, Nottingham, NG11 8NS,UK. E-mail: john.wallis@ntu.ac.uk

\begin{abstract}
Introduction of chirality into conducting systems is a topic of much current interest as it allows the preparation of multifunctional materials in which the chirality may modulate the structural disorder or expresses its influence through the electrical magneto-chiral anisotropy effect. The access to various chiral electroactive precursors for molecular conductors is therefore of paramount importance. Different families of chiral tetrathiafulvalene (TTF) derivatives are reviewed together with the corresponding synthetic strategies. Systems based on stereogenic carbon or sulfur atoms, axial and supramolecular chirality have been developed. In other systems the use of achiral TTFs with chiral anions have provided molecular conductors, although in most of them to date the anion is present in racemic form. Starting from some of these precursors several chiral conductors have been prepared and in two cases, involving either chiral TTF-oxazolines salts or BEDT-TTF salts with metal-oxalate anions and chiral solvent molecules, differences between the conductivity of the racemic and enantiopure forms have been found, as a consequence of the structural disorder in the solid state. Further developments in this field are expected to be directed especially towards helical architectures, possibly based on supramolecular chirality, and systems combining conductivity, magnetism and chirality in both organic and inorganic lattices.
\end{abstract}




\section{Introduction}

The synthesis of electroactive chiral precursors for molecular conductors is currently receiving much interest within the general framework of multifunctional materials, a field which has been continuously developing over the last two decades. ${ }^{1}$ The basic idea consists of the combination within the same material of at least two different physical properties, in the present case conductivity and chirality, which can then coexist or interplay. The synergistic association of these two properties could lead to the observation of a new phenomenon, referred to as the electrical magneto-chiral anisotropy effect, which has been recently experimentally observed by Rikken et al. in the magneto-transport properties of chiral carbon nanotubes. ${ }^{2}$ This effect is related to the direct influence of the handedness of a chiral conductor on its conductivity, measured under an applied magnetic field parallel to the direction of the current. Accordingly, small differences between the conductivity of the opposite enantiomers, and also the racemic compound, may be observed. Although the magnitude of this effect is expected to be very small, and therefore rather challenging to observe it experimentally, interest from the field of spintronics has been mentioned. ${ }^{3}$ In the same general field of the magneto-anisotropy phenomena, experimental evidences for a chiral Hall effect, when the applied magnetic field is perpendicular to the current flowing direction, would be of much interest. ${ }^{4}$ Note also that the preparation of chiroptical conductors as switchable and tuneable systems is also an appealing direction of investigation. ${ }^{5}$ Since the large majority of organic conductors reported so far, be they semiconductors, metals, and even superconductors, ${ }^{6}$ is based on tetrathiafulvalene (TTF) derivatives ${ }^{7}$ it is of obvious interest to address and discuss the introduction of chirality into this class of sulfur rich organic electron donors. In this respect one of the main objectives related to chiral TTFs clearly relies on their use as precursors in the preparation of chiral conductors. However, the possible influence of the chirality on the conducting properties of TTF based materials has been addressed by Dunitz already in the middle of the eighties, through the synthesis of the first enantiopure TTF, a tetramethylated derivative of the bis(ethylenedithio)-tetrathiafulvalene (BEDT-TTF or ET). ${ }^{8}$ From a structural point of view differences between enantiopure and racemic forms may occur, since it is known that the racemates can sometimes accommodate enantiomers exchanging places, ${ }^{9,10}$ and hence an inherent source of disorder, which is absent in crystals of pure enantiomers. Taking into account that the electronic conductivity is strongly influenced by the structural disorder, ${ }^{11}$ the presence of chiral centres could thus affect the former through the modulation of the latter. We will discuss in this paper the main synthetic strategies developed so far towards chiral TTFs, by 
pointing out the different chiral groups or chirality type involved, and then we will focus on several chiral conducting systems prepared from some of these precursors. Alternative strategies for the introduction of chirality into TTF based conductors, such as the use of chiral anions in radical cation salts or systems built with supramolecular chirality, will be also discussed. We would like to stress that other interesting and very promising electroactive chiral systems exist and some of them were the focus of recent review articles. We already mentioned the results of Rikken et al. on conducting single-walled nanotubes having helical chirality. In the paragraph concerning supramolecular chirality we will briefly discuss the case of the nanocoils formed by hexabenzocoronene derivatives, a system in which the mobility of the charge carriers might parallel that in helical carbon nanotubes. The annelated helical $\beta$-oligothiophenes have been recently reviewed by Rajca et al., ${ }^{12}$ while formation of chiral aggregates based on sexithiophene derivatives was reported by Meijer et al. ${ }^{13}$ Chiral polyaniline assemblies have been obtained upon adding camphor sulfonic acid as chiral dopant in the polymerization process. ${ }^{14}$ Finally, one should mention also the huge amount of work dedicated to the investigation of the supramolecular helicity in derivatives of oligo(p-phenylenevinylenes). ${ }^{15}$

\section{Chiral TTF precursors}

\subsection{BEDT-TTF related donors with stereogenic carbon atoms}

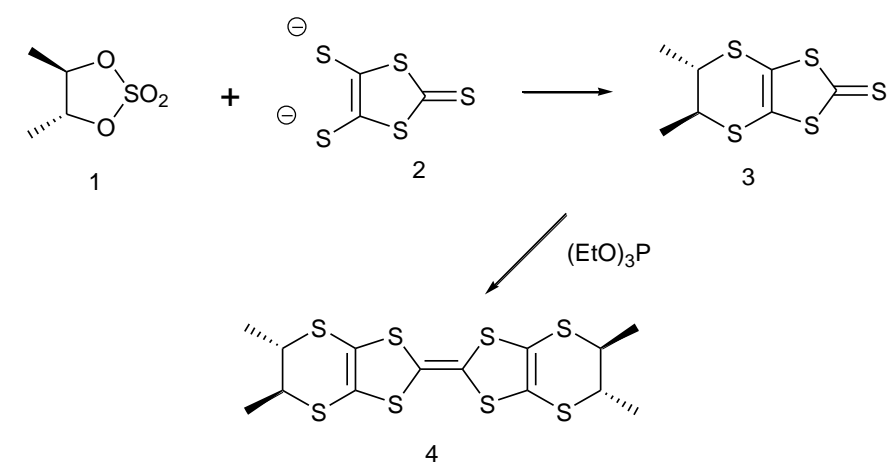

Scheme 1 Synthesis of chiral donor 4.

Substitution at any of the four methylene carbon atoms in BEDT-TTF creates a stereogenic centre, and this has been an important strategy for the production of chiral donor molecules. Dunitz prepared and studied the first enantiopure donor in this series, the $(S, S, S, S)$-tetramethyl derivative $4{ }^{8}$ The synthesis involved reaction of the enantiopure cyclic sulfate ester $\mathbf{1}$, prepared from $(R, R)$-butane-2,3-diol, with the dithiolate 2, prepared in three steps from carbon disulfide, to give the chiral bicyclic thione 3 in $30 \%$ yield by two consecutive $S_{N} 2$ reactions. Coupling of 
the thione $\mathbf{3}$ in triethyl phosphite gave the enantiopure donor $\mathbf{4}$ in $40 \%$ yield. In a similar way the $(R, R, R, R)$-tetrakis(methoxymethyl)-BEDT-TTF 5 has been prepared, though in low yield. ${ }^{16}$ Extension of this general synthetic approach has yielded the mono-substituted enantiopure donors $6^{17}$ and $\mathbf{1 7}^{18}$ with $-\mathrm{CH}_{2} \mathrm{OH}$ or $-\mathrm{CH}_{2} \mathrm{CO}_{2} \mathrm{CH}_{3}$ side chains, and the polysubstituted unsymmetrical donors $\mathbf{7 - 9}^{19,20}$ by using a cross coupling reaction to connect the two heterocyclic systems. For example, the enantiopure cyclic sulfate ester of methyl 3,4-dihydroxybutanoate reacted with dithiolate 2 to give the corresponding thione $\mathbf{1 4}$ which was converted to an oxo compound 15 using mercuric acetate. Cross coupling with the unsubstituted thione $\mathbf{1 6}$ in triethyl phosphite gave the monosubstituted donor $\mathbf{1 7}$ after chromatographic separation from homocoupled products. A related procedure with the cyclic sulfate ester of $(R, R)$-1,4-difluorobutane-2,3-diol unexpectedly gave the thione $\mathbf{1 0}$ which was transformed to the donor 11. ${ }^{21}(S, S)$-Dimethyl-BEDT-TTF 12 was prepared in a different way, due to difficulties in separation of the homo- and cross-coupled products. ${ }^{22}$ Thus, the chiral donor 13 in which two thiolate groups are masked with trimethylsilylethoxymethyl protecting groups, was prepared by cross coupling procedures, and then the protecting groups removed using fluoride and the resulting dithiolate reacted with 1,2-dibromoethane.

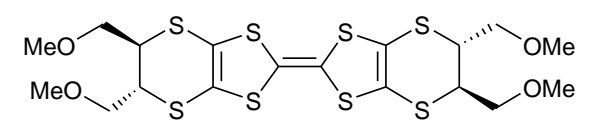

5<smiles>C[C@@H]1SC2=C(SC(=C3SC4=C(OC=CO4)S3)S2)S[C@@H]1C</smiles>

7

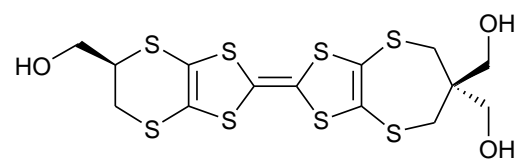

9

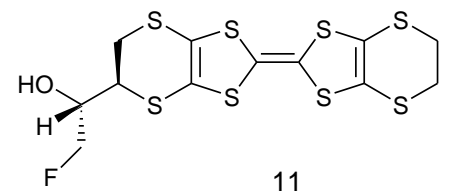

11<smiles>OC[C@H]1CSC2=C(SC(=C3SC4=C(SCCS4)S3)S2)S1</smiles>

6<smiles>C[C@H]1SC2=C(SC(=C3SC4=C(SCC(CO)(CO)CS4)S3)S2)S[C@@H]1C</smiles>

8<smiles>O[C@H](CF)[C@H]1CSc2sc(=S)sc2S1</smiles><smiles>C[C@H]1SC2=C(SC(=C3SC4=C(SCCS4)S3)S2)S[C@@H]1C</smiles>

12

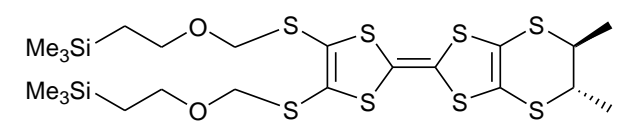




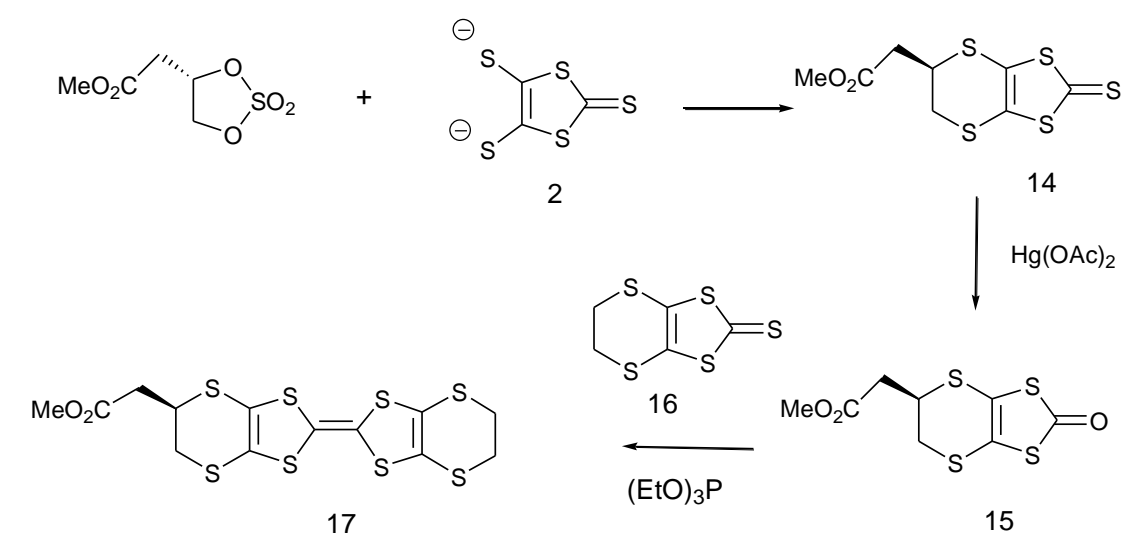

Scheme 2 Synthesis of chiral donor 17.

An alternative approach to the chiral thione precursors is to use diastereoselective cycloaddition reactions of trithione 18, available to two steps from carbon disulfide, with enantiopure alkenes. Thus, (-)- $\beta$-pinene reacts with total diastereoselectivity with trithione 18 to give a good yield of the thione $\mathbf{1 9}$, which has been successfully transformed to a donor, $\mathbf{2 0}{ }^{23}$ Apopinene 21 will also react with the trithione 18 to give the thione 22, which has been subsequently transformed to the non-racemic donor $\mathbf{2 3}$ (Scheme 3). ${ }^{24}$ However, it is difficult to obtain apopinene enantiomerically pure, due to its easy racemisation by a shift of the double bond in the six membered ring. An extension of this approach is illustrated by reaction of the enol acetate of (+)-nopinone, 24, with the trithione (Scheme 4). Cycloaddition is followed by the formal cis elimination of acetic acid, presumably by the nearest sulfur atom assisting in the elimination of acetate followed by proton loss, to give the thione $\mathbf{2 5}$ which has a double bond at the fusion of the dithiin and carbocyclic rings. This material has been elaborated into the enantiopure donor $\mathbf{2 6} .^{24}$ This approach should be extendable to other systems. Reaction of the trithione 18 with the chiral alkene 27, prepared in three steps from $D$-mannitol, shows 6:1 diastereoselectivity in favour of the thione $\mathbf{2 8}$ over thione $29 .^{23}$ This is an important reaction since it allows preparation of the donors $\mathbf{3 0}$ and $\mathbf{3 1}$, by coupling reactions and subsequent deprotection, which are particularly attractive since they contain chirally disposed sets of four hydrogen bond donating groups (Scheme 5). 


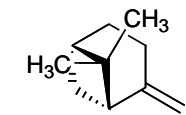

$\left.\right|_{s^{\prime}} ^{s^{s}}=s \quad 18$

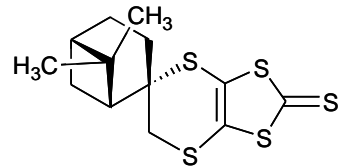

19

$\downarrow$<smiles>CC1(C)[C@@H]2CC[C@H]1C(C)(C)[C@]21CSC2=C(SC(=C3SC4=C(SCCS4)S3)S2)S1</smiles>

20
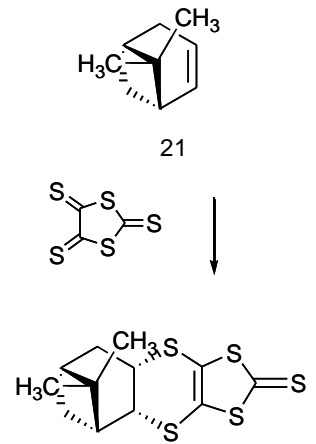

22<smiles>C[In]</smiles>

Scheme 3 Preparative routes to chiral donors 20 and 23.

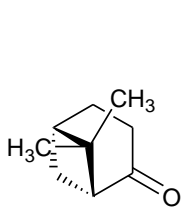

(+) Nopinone

$$
\begin{aligned}
& \mathrm{H}_{3} \mathrm{C}^{\stackrel{\mathrm{O}}{\mathrm{O}}} \\
& \underset{\text { tosic acid / reflux }}{\stackrel{\mathrm{H}_{3} \mathrm{C}}{\longrightarrow}}
\end{aligned}
$$

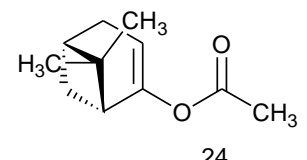

$\mathrm{s}_{\mathrm{s}}^{\mathrm{s}}=\mathrm{s}$
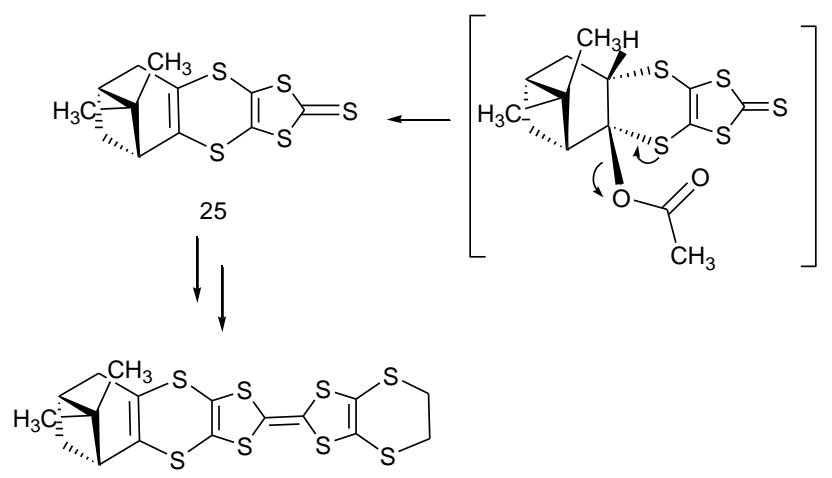

26

Scheme 4 Preparative route to chiral donor 26. 

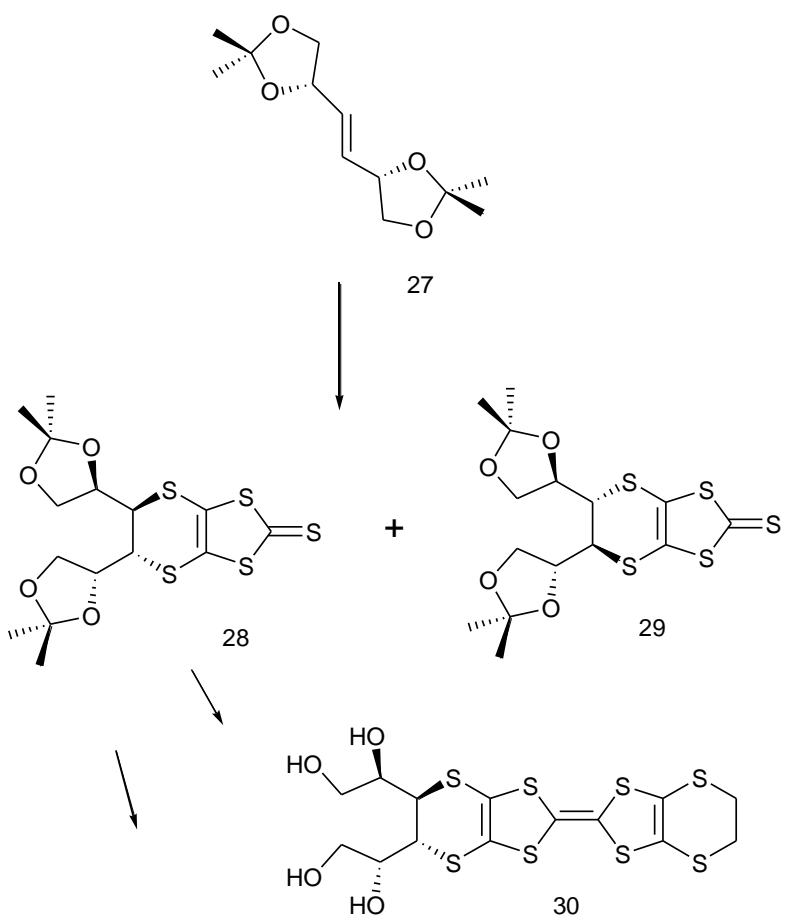<smiles>OC[C@H](O)[C@H]1SC2=C(SC(=C3SC4=C(S3)S[C@H]([C@H](O)CO)[C@@H]([C@@H](O)CO)S4)S2)S[C@H]1CO</smiles>

Scheme 5 Preparative routes to chiral donors $\mathbf{3 0}$ and $\mathbf{3 1 .}$

Related chiral donors with expanded outer rings have also been prepared. Thus, the dithiolate 2 reacts with the bis(mesylate) of $(R, R)$-pentane-2,4-diol to provide the thione $\mathbf{3 2}$ with an outer seven-membered ring which has been transformed into homo and heterocoupled donors $\mathbf{3 3}$ and 34 (Scheme 6). The molecular structure of 33, determined by X-ray crystallography, adopts a very bowed structure, with both seven membered rings in chair conformations, so that each ring contains an axial and an equatorial methyl group (Fig. 1). ${ }^{24}$ Nevertheless, in its oxidized state, a more planar structure is expected, but retaining the equatorial and axial groups with the potential for steering the formation of helical stacks. Since the thione $\mathbf{3 2}$ has $C_{2}$ symmetry, it is a candidate for cross-coupling with less symmetrical chiral oxo compounds, thus donor $\mathbf{3 5}$ has been prepared from 25 and 32. Similarly, reaction of the dithiolate 2 with the 2,3-bis(tosylate) 36 gave the expected thione 37 with an outer eight-membered ring. This was elaborated into chiral donors $\mathbf{3 8}$ and $\mathbf{3 9}$ with two or four hydroxyl groups (Scheme 7). ${ }^{25}$ 


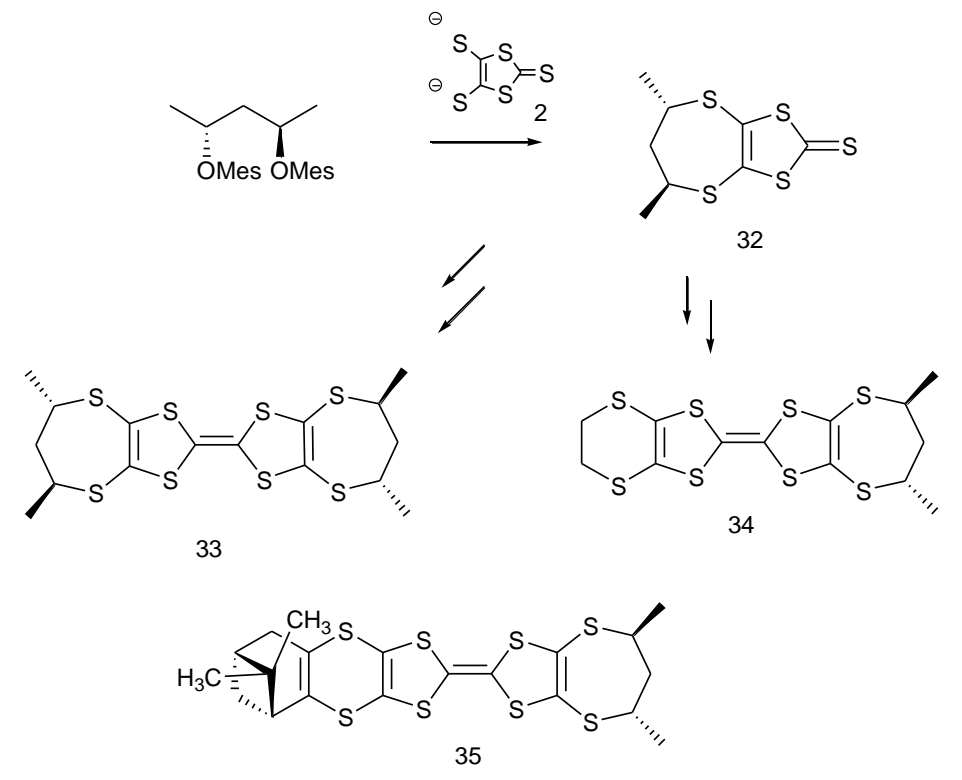

Scheme 6 Preparative routes to chiral donors 33-35.

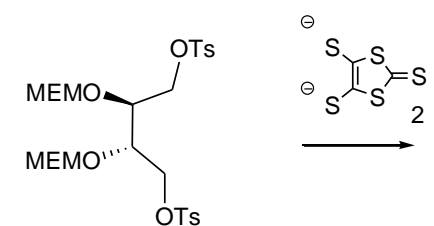

36

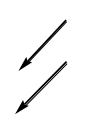

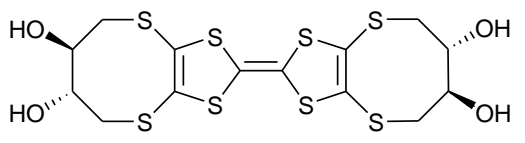

38

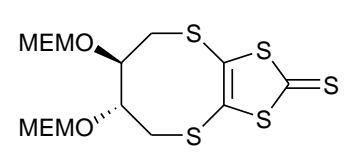

37

$\downarrow$

Scheme 7 Preparative routes to chiral donors $\mathbf{3 8}$ and $\mathbf{3 9 .}$

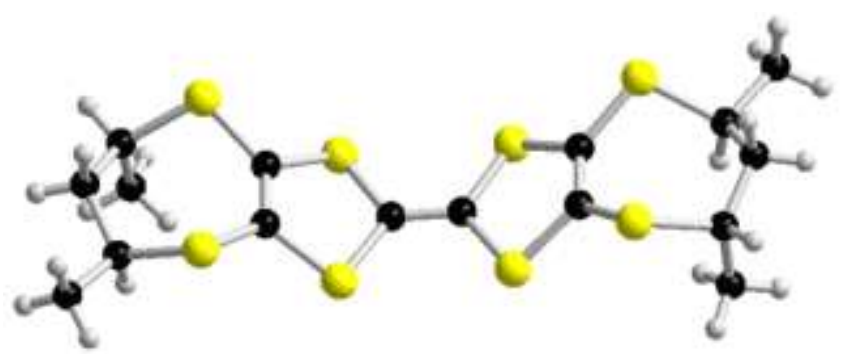

Fig. 1 Molecular structure of donor 33.<smiles>O=C1CSC2=C(SC1)SC(=C1SC3=C(SCC(=O)CS3)S1)S2</smiles>

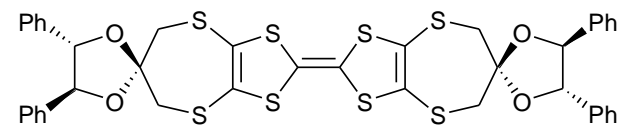


A further strategy is to attach a chiral moiety to an achiral donor, and this has been achieved by ketalisation of both carbonyl groups of the donor $\mathbf{4 0}$ with $(S, S)$-1,2-diphenylethane-1,2-diol to give donor $41 .{ }^{18}$

\subsection{BEDT-TTF donor with a stereogenic sulfur atom.}

It is clear from the previous paragraph that a rich variety of functionalized chiral BEDT-TTF derivatives is now available for attempting to prepare enantiopure radical cation salts or charge transfer compounds in order to investigate the influence of the chirality in the conducting properties. However, in all these chiral BEDT-TTF donors, the chiral information is rather remote from the TTF redox active core, which contain the potentially $\pi$ mobile electrons. One might anticipate that closer location of the chiral centers to the electron conduction pathways would provide a better opportunity to observe a magneto-chiral anisotropy effect in the conductivity. In this respect, the parallel with the recent observation of huge enhancement of the magneto-chiral dichroism in enantiopure ferromagnets, in which magnetic and chiral centers coincide, seems particularly pertinent. ${ }^{26}$ Therefore, an interesting alternative to introduce chiral information directly on the TTF core has been recently highlighted by one of us through the selective transformation to sulfoxide of one of the four internal sulfur atoms of BEDT-TTF, thus leading to a chiral sulfur atom. ${ }^{27}$ Note that the sulfoxidation reaction with $m$-chloroperbenzoic acid of the parent TTF into TTF monosulfoxide was reported in the late seventies, ${ }^{28,29}$ though without any mention of chirality issues. Very interestingly, the use of (+)-(8,8-dichlorocamphoryl-sulfonyl)oxaziridine $\mathbf{4 2}$ as sulfoxidation agent ${ }^{30}$ in the case of BEDT-TTF afforded the inner monosulfoxide $\mathbf{4 3}$ in a complete chemo- and regioselective manner (Scheme 8).

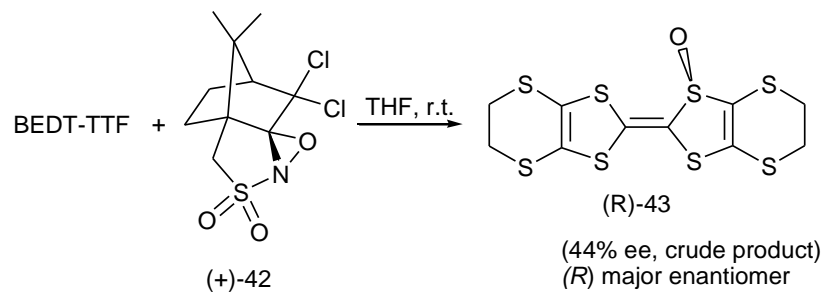

Scheme 8 Synthesis of $\mathbf{4 3}$.

Moreover, chiral HPLC analyses of the reaction product purified by column chromatography indicated an enantiomeric excess of about $44 \%$, which represents a remarkable result at this stage. Furthermore, enrichment up to about $70 \%$ ee could be reached in the mother liquors after two recrystallizations. Mixtures enriched in the opposite enantiomer have been obtained when 
the (-)-oxaziridine was used. Although oxidation of prochiral sulfides with (+)-oxaziridines generally leads to the selective formation of the $(S)$ enantiomer, ${ }^{31}$ circular dichroism measurements combined with time dependent DFT calculations demonstrate that in the case of 43 the formation of the $(R)$ enantiomer is favoured. ${ }^{32}$ On the contrary, no enantioselectivity was observed in the formation of the monosulfoxides of TTF, tetramethyl-TTF (TMTTF) or tetrakis(thiomethyl)-TTF under the same conditions. ${ }^{32}$ This suggests that the rigid ethylenedithio bridge plays an important role at this level. The structure of the inner sulfoxide 43 was unambiguously determined by single crystal X-ray measurements on racemic crystals grown either from solutions of enantioenriched or racemic mixtures of $\mathbf{4 3}$ (Fig. 2).

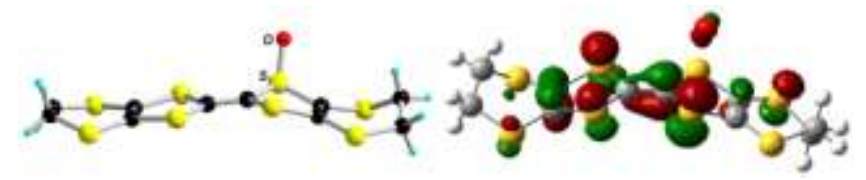

Fig. 2 Molecular structure (left) and HOMO of the optimized structure (right) of $\mathbf{4 3}$.

Worth noting is the shape of the HOMO (DFT/B3LYP/6-31+G*) which is of $\pi$ type and develops mainly on the TTF core, yet with a non-negligible contribution of the chiral SO group (Fig. 2). The same observation is valid also for the SOMO of the optimized radical cation of $\mathbf{4 3}$ and demonstrates that in principle the sulfoxidation route allows for the direct involvement of the chiral group in the electron delocalization. Unfortunately, electrochemical oxidation suggests that the radical cations of such inner TTF-sulfoxides are not stable in the cyclic voltammetry conditions and decompose to give back the starting TTF. ${ }^{27,32}$ A possible explanation of this unexpected behavior could rely on the relatively high value of $+0.95 \mathrm{~V}(v s$. $\mathrm{SCE}$ ) of the oxidation potential required to generate the radical cation, which could induce a kinetic instability of the oxidized species. However, a crystalline charge transfer salt could be obtained when mixing solutions of $\mathbf{4 3}$ and tetrafluoro-tetracyanoquinodimethane $\left(\mathrm{TCNQF}_{4}\right)$ in $\mathrm{CH}_{2} \mathrm{Cl}_{2}$, followed by slow evaporation of the solvent. The estimated degree of charge transfer, from X-ray and IR data, amounts to $\rho=-0.5 \mathrm{e}$, which is rather unusual for compounds containing $\mathrm{TCNQF}_{4}$, a strong chemical oxidant, but this is very likely due to the high oxidation potential of 43. Although this charge transfer compound is an insulator, its formation demonstrates that isolation of solid radical cations salts or charge transfer compounds derived from inner TTF-sulfoxides should be possible. Worth mentioning is that an interesting alternative to avoid decomposition of the oxidized species could consist of the introduction of the oxygen atom on an outer sulfur atom of BEDT-TTF, in order to lower the oxidation potential of the TTF-sulfoxide. 


\subsection{TTF donors with chiral oxazoline rings}

The first examples of TTFs containing appended chiral oxazoline rings (44-46) have been described by Bryce et al. and were synthesized starting from the acid chloride of TTF and chiral amino alcohols of $(S)$ configuration, followed by cyclisation of the intermediate $\beta$-hydroxyamides in the presence of $\mathrm{PPh}_{3}, \mathrm{CCl}_{4}$ and $\mathrm{Et}_{3} \mathrm{~N}$ (Appel conditions) (Scheme 9). ${ }^{33}$

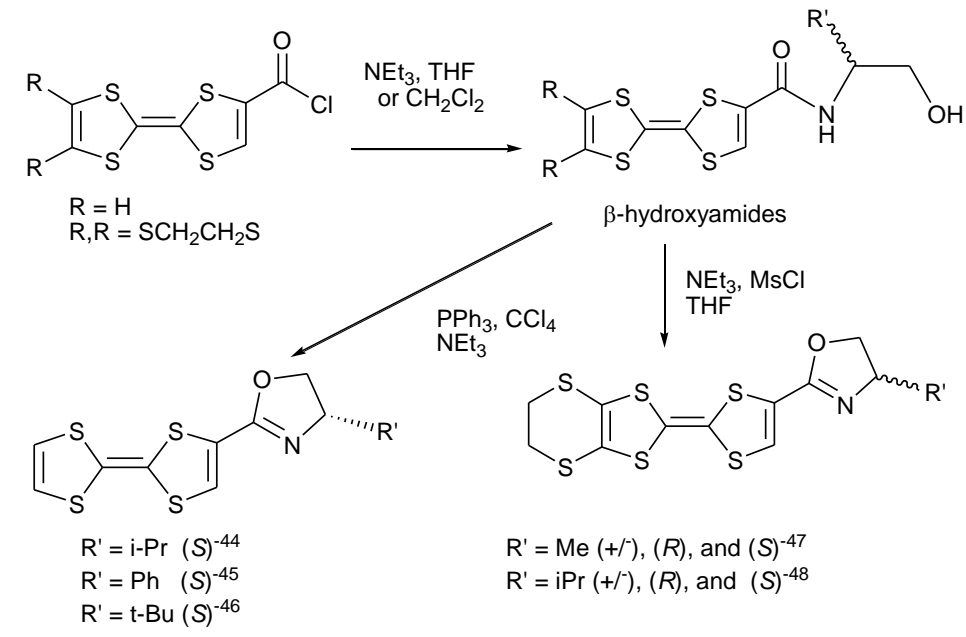

Scheme 9 Synthesis of TTF-oxazolines.

This series of chiral TTFs was prepared with the clear objective to use the oxazolines as ligands in the catalytic asymmetric allylic alkylation reaction, yet the results in terms of activity and enantioselectivity were rather modest. One can tentatively ascribe this to the poor coordination ability of the TTF sulfur atoms, unable to ensure a fairly strong chelation of the palladium center, which is in principle beneficial for good catalytic activity in this reaction. No mention of the possible use of the compounds 44-46 as precursors for molecular conductors has been made in this report. More recently, Fourmigué and Avarvari described the synthesis of two complete series of EDT-TTF-oxazolines, with either methyl (47) or isopropyl (48) substituents on the oxazoline ring, as racemic and enantiopure $(R)$ and $(S)$ derivatives. ${ }^{34,35}$ The choice of the methyl substituent was justified by its minimum steric hindrance with respect to the packing of the molecules in the solid state. On the contrary, the isopropyl substituent was preferred for the potential catalytic applications of these ligands and especially their phosphino derivatives as chelating phosphino-oxazolines. The synthetic procedure involved first reaction of the EDT-TTF acid chloride with alaninol and valinol, racemic or enantiopure, and then subsequent cyclization of the $\beta$-hydroxyamides in the presence of triethylamine and methanesulfonyl chloride $(\mathrm{MsCl})$ (Scheme 9). Thus, the chiral information is perfectly controlled throughout the synthesis and easily introduced by the use of racemic or enantiopure amino alcohols. The solid 
state structures of both series of donors were determined by single crystal X-ray diffraction. Particularly notable is the planar arrangement between the TTF and oxazoline units, within $s$-trans conformations (Fig. 3). Crystallization of the enantiopure $(R)$ and $(S)$ donors occurs in chiral non-centrosymmetric space groups, i.e. monoclinic $P 2_{1}$ for $\mathrm{Me}$ and orthorhombic $P 2{ }_{1}{ }_{1} 2_{1}$ for ${ }^{i} \operatorname{Pr}$ series.

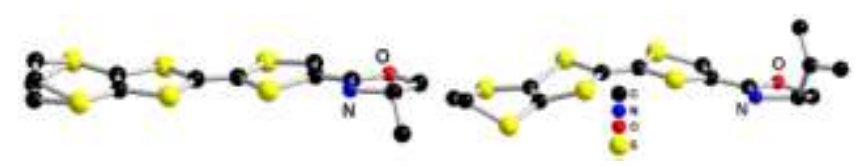

Fig. 3 Molecular structures of $(S)-\mathbf{4 7}$ (left) and $(R)-\mathbf{4 8}$ (right). Hydrogen atoms have been omitted.

All these donors show the classical electrochemical behavior of a TTF, with a first reversible oxidation wave at $+0.66 \mathrm{~V} v s$. SCE and a second one, also reversible, at $+1.14 \mathrm{~V} v s$. SCE, which is indicative of good electron donating properties, and hence their interest as precursors for molecular conductors (see Section 3). Alternatively, the mono-oxazolines have been further transformed into phosphino-oxazolines 49-50 (Scheme 10), ${ }^{34}$ which showed in the case of the isopropyl derivatives interesting abilities as electroactive ligands in a couple of catalytic reaction involving palladium ${ }^{36}$ or iridium $^{37}$ centres.

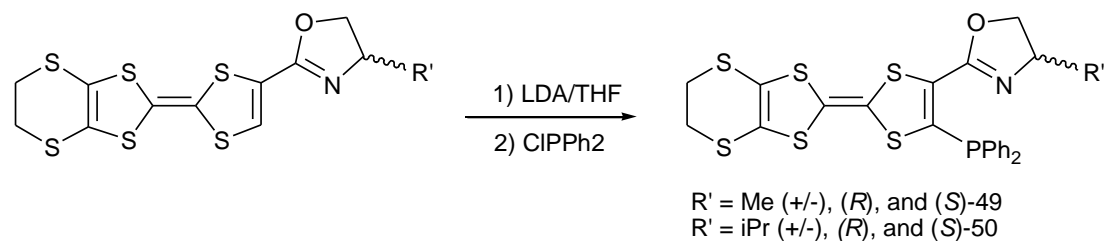

Scheme 10 Synthesis of EDT-TTF-thiomethyl-oxazolines.

An interesting development is the synthesis of two complete series of EDT-TTF-thiomethyl-oxazolines $\mathbf{5 1}$ and 52, with methyl and isopropyl substituents respectively, starting from appropriately substituted thione and oxo compound halves and paralleling the procedure previously applied (Scheme 11). ${ }^{38}$ These compounds have been primarily synthesized with the objective of investigating the possible occurrence of 1,5-nonbonded intramolecular interactions of $\mathrm{S} \cdots \mathrm{O}$ or $\mathrm{S} \cdots \mathrm{N}$ type, prone to provide planar $s$-trans or $s$-cis conformations, respectively. 


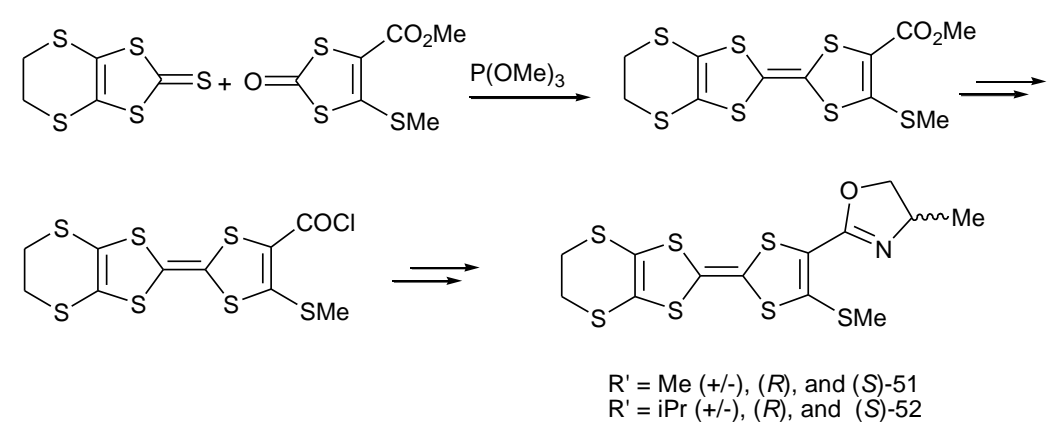

Scheme 11 Synthesis of EDT-TTF-thiomethyl-oxazolines.

Single crystal X-ray structures of both $\mathbf{5 1}^{38}$ and $\mathbf{5 2}^{37}$ revealed that in the solid state the establishment of S $\cdots \mathrm{O}$ nonbonded interactions, characterized by short intramolecular $\mathrm{S} \cdots \mathrm{O}$ contacts and linear O $\cdots \mathrm{S}-\mathrm{Me}$ motifs, is favoured over that of S $\cdots \mathrm{N}$ interactions (Fig. 4). Indeed, values of $2.87 \AA((S)-\mathbf{5 1})$ or $2.84 \AA((S)$-52) are measured for the $\mathrm{S} \cdots \mathrm{O}$ distance, while the corresponding $\mathrm{O} \cdots \mathrm{S}-\mathrm{Me}$ angles amount to $176.2^{\circ}$ and $168.4^{\circ}$, respectively. This peculiar feature is very likely responsible for the overall planar conformation of the donors, with torsion angles $\mathrm{TTF}_{\text {mean }} \cdots \mathrm{OX}_{\text {mean }}$ and $\mathrm{TTF}_{\text {mean }} \cdots \mathrm{SMe}$ close to $0^{\circ}$.

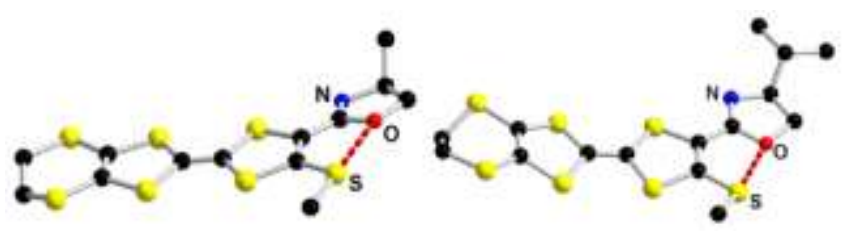

Fig. 4 Molecular structures of $(S)-51$ (left) and $(S)$-52 (right) with an emphasis on the short S...O contacts.

Hydrogen atoms have been omitted.

Once again, the enantiopure compounds crystallized in the non-centrosymmetric chiral space groups $P 2{ }_{1} 2_{1} 2_{1}(\mathbf{5 1})$ and $P 2_{1}(\mathbf{5 2})$. Although in the solid state structures of the neutral EDT-TTF-thiomethyl-oxazolines only the s-trans conformation, corresponding to $\mathrm{S} \cdots \mathrm{O}$ contacts, is observed, theoretical calculations at DFT/B3LYP/6-31+G* level show that both possible planar conformations, i.e. s-cis and s-trans, are isoenergetic minima, with an energy barrier of about $7 \mathrm{kcal} \mathrm{mol}^{-1}$ between them. Therefore, the conformation observed experimentally is probably the consequence of packing effects. Very interestingly, the signature of $\mathrm{S} \cdots \mathrm{O}$ or $\mathrm{S} \cdots \mathrm{N}$ nonbonded interactions in this series of donors was theoretically supported by an "Atoms in Molecules" (AIM) topological analysis. ${ }^{39}$ The same type of calculations performed in the case of radical cations of TTF-thiomethyl-oxazolines indicates also planar conformations as energy minima, with a slight stabilization of the s-cis conformation with respect to the s-trans one, thus suggesting that observation of the s-cis conformation in the solid state structures of radical cation salts of $\mathbf{5 1}$ and $\mathbf{5 2}$ might be possible. 
As mentioned earlier, TTF-phosphino-oxazolines have been used as ligands for $\mathrm{Pd}(\mathrm{II})$ and $\operatorname{Ir}(\mathrm{I})$ centers in two catalytic reactions, taking advantage of the well known efficiency of phosphino-oxazolines in these catalytic processes. The thiomethyl derivatives $\mathbf{5 2}$ have been also tested for the same transformations, i.e. asymmetric allylic substitution and hydrogenation of imines, but the results were much less convincing than for the phosphino counterparts. On the other hand, the series of ligands $\mathbf{5 1}$ was used in coordination complexes with the paramagnetic centers $\mathrm{Cu}(\mathrm{II})$ and $\mathrm{Co}(\mathrm{II})$ within the more general area of multifunctional molecular materials, ${ }^{1}$ thus providing chiral electroactive paramagnetic complexes. ${ }^{40}$ Cyclic voltammetry measurements on the thiomethyl derivatives and their different metal complexes indicate good electron donating properties, with a first oxidation potential around $+0.60-0.65 \mathrm{~V}$ $v s$. SCE, and stability of the radical cation species. It appears, thus, that the family of TTF-oxazolines and derivatives represents promising precursors for chiral conductors, with the additional functionality to engage in coordination complexes with various metal centers.

\subsection{TTF donors attached to axially chiral binaphthyl systems}

Enantiopure TTF dimers containing the 1,1'-binaphthyl chiral spacer have been first reported by Martin et al., with the objective to access new precursors with enhanced dimensionality due both to the dimeric nature of the compounds and to the rigidity and non-planarity of the linker. ${ }^{41}$

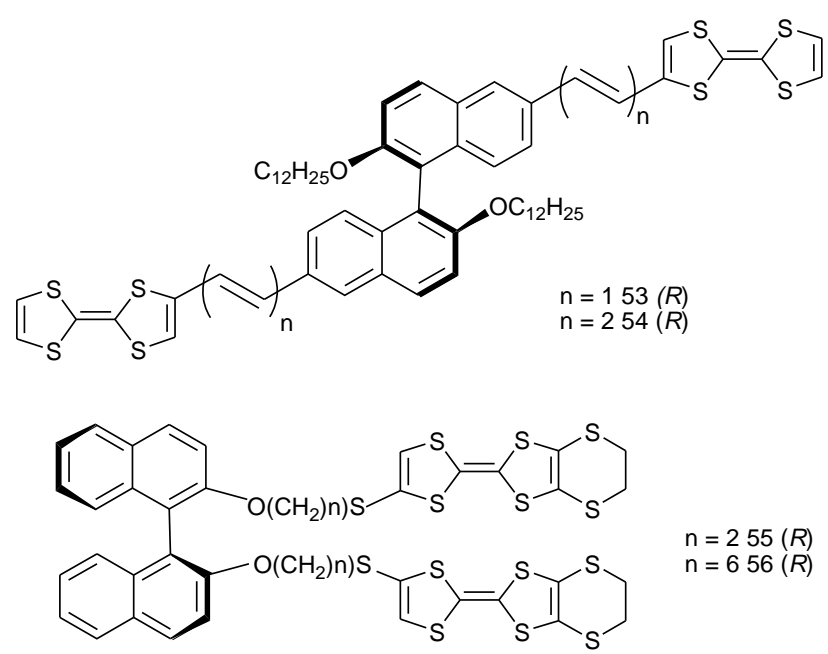

Scheme 12 TTF dimers containing the chiral 1,1'-binaphthyl scaffold.

The two compounds $\mathbf{5 3}$ and $\mathbf{5 4}$ shown in Scheme 12 have been synthesized by Wittig or Wittig-Horner coupling reactions between $(R)-2,2$ '-bis(dodecyloxy)-1,1'-binaphthyls, substituted with triphenylphosphonium or methylphosphonate groups in the positions $6,6^{\prime}$, and formyl TTF or vinyl-formyl TTF. The TTF moieties oxidize simultaneously to the 
corresponding radical cations at potentials of $+0.48-0.52 \mathrm{~V}$, as ascertained by cyclic voltammetry measurements. Although the possibility of formation of charge transfer compounds with the acceptor dichlorodicyano- $p$-benzoquinone (DDQ) has been mentioned, ${ }^{41 \mathrm{a}}$ no further report addressed this issue so far. A series of mono-, bis- and tetrakis-TTFs based also on the $(R)$ enantiomer of the 1,1'-binaphthyl-2,2'-dioxo skeleton has been synthesized by Zhang and Zhu with the aim of investigating the modulation of the circular dichroism properties with the oxidation state of the donors. ${ }^{42}$ Accordingly, the compound $\mathbf{5 5}$ (Scheme 12) showed interesting chiroptical switch behavior, a likely consequence of the modulation of the dihedral angle between the naphthalene moieties, inducing a variation in intensity of the circular dichroism signal with the oxidation state of the TTFs. Formation of strong dicationic $\pi$-dimers when all TTFs were monooxidized and electrostatic repulsion for the resultant 4+ state seem to be at the origin of the observed modulation. When a longer linker was used as in 56, the same modulation was no longer observed, since, obviously, the flexibility of the long alkyl chains ensured a buffer effect between the binaphthyl backbone and the TTFs. Despite the fact that none of the binaphthyl based TTFs has been engaged in conductor materials so far, it is clear that they represent a promising class of chiral precursors. It would be also interesting to study the solid state organization of such derivatives to see the influence of the chiral unit on the packing of the donors.

\subsection{TTF donors with chiral side chains}

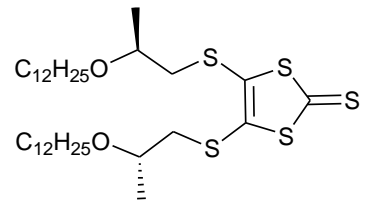

57
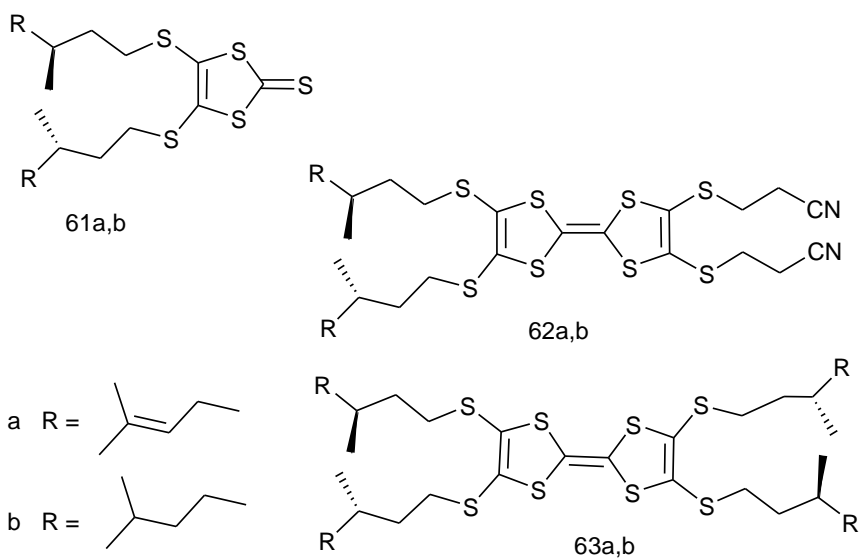
There are surprisingly few reports of TTFs with chiral side chains, yet these could be important components for self assembled conducting systems, for example for preparing liquid crystalline phases, in helical arrangements in gels or crystals, or in monolayers. Most have been prepared from the dithiolate $\mathbf{2}$ or its zinc complex. Thus, Amabilino has reported the preparation of thiones 57 and $\mathbf{6 1}$ by alkylation of the zinc complex of $\mathbf{2}$ with appropriate bromo compounds, and their cross coupling to give donors such as 58-60 and 62. Homocoupling of 61 would be expected to be successful and small quantities of donors such as $\mathbf{6 3}$ were obtained as byproducts from the cross coupling reactions. ${ }^{43}$ Reaction of dithiolate 2 with $(S)$-propylene-oxide has given the thione 64, which has been used in the preparation of donors $\mathbf{6 5}$ and $\mathbf{6 6}$ (Scheme 13). ${ }^{44}$ The molecular structure of $\mathbf{6 5}$ and the crystal structure of a 1:1 TCNQ complex of $\mathbf{6 6}$ with alternating molecules in the stack are shown in Figures 5 and 6.
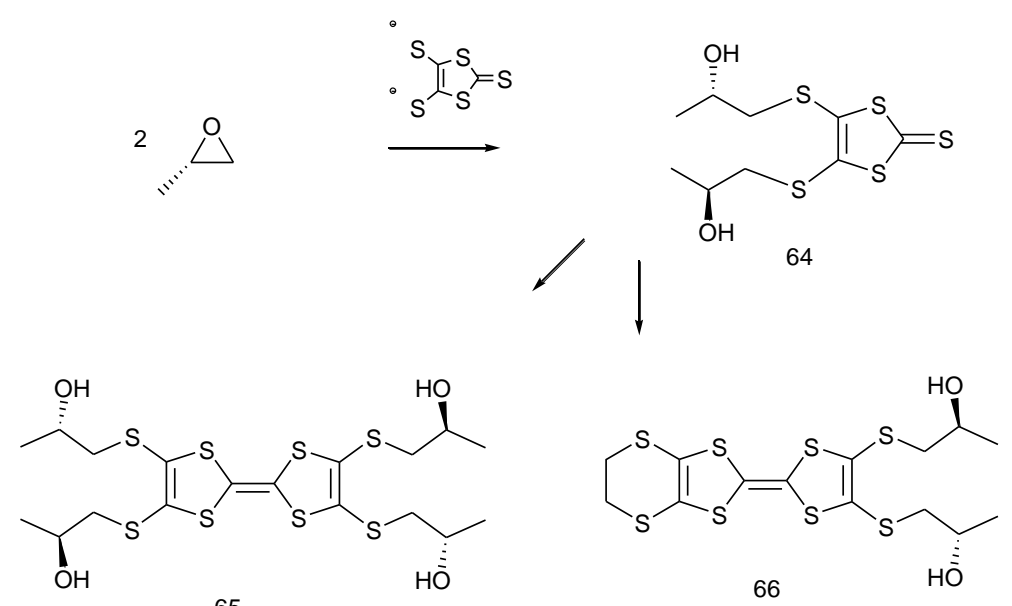

Scheme 13 Synthesis of chiral TTFs 65 and 66.

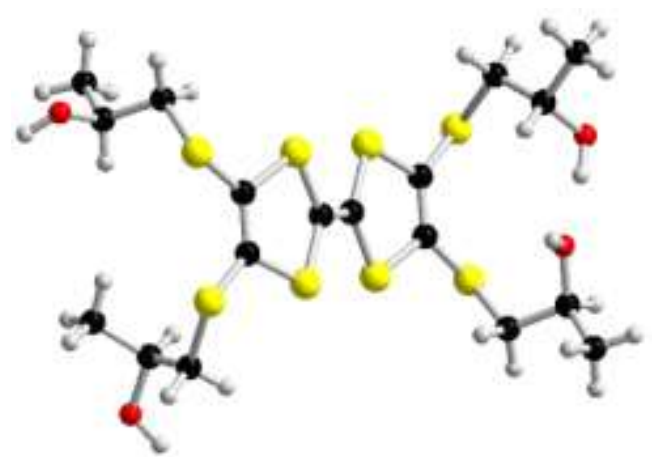

Fig. 5 Molecular structure of $\mathbf{6 5}$. 


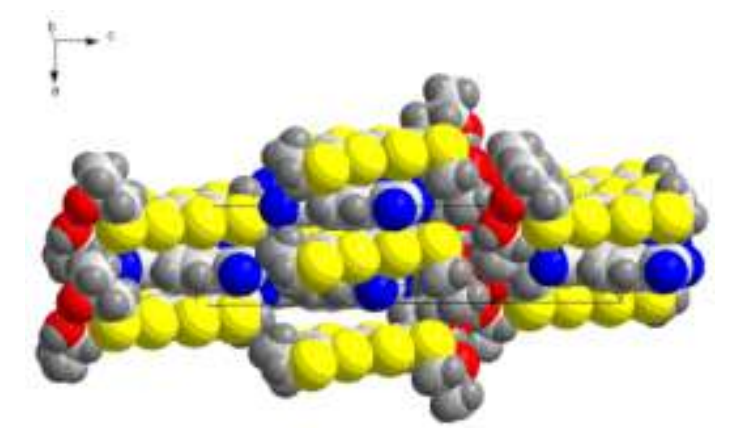

Fig. 6 1:1 TCNQ complex of $\mathbf{6 6}$ with alternating donors and acceptors in the stack.

Kilburn et al., with the long term aim of utilizing the supramolecular structures possible in polypeptides for controlling the relative orientation of TTFs, have prepared 67 a bis-protected $L$-aspartic acid bearing an organosulfur unit in the ester side chain, and then used it to form the di-, tri- and tetra peptides 68-70. ${ }^{45}$ Electrochemical studies of 67-70 are interpreted as indications of molecular reorganization on oxidation to facilitate the intramolecular interaction between the uncharged and charged organosulfur donors. In a particularly impressive piece of work Kato has designed chiral TTFs for forming fibrous aggregates in aromatic liquid crystals and has doped them with iodine or TCNQ and measured conductivities of up to $10^{-5} \mathrm{~S} \mathrm{~cm}^{-1}$. $^{46}$ Thus TTF 71 forms fibrous aggregates in the 4-cyano-4'-n-propylbiphenyl in which molecules are held together by hydrogen bonding in a beta-pleated sheet arrangement. Doping with iodine initially gives the full charge transfer state and an increase in conductivity to $2 \times 10^{-7} \mathrm{~S} \mathrm{~cm}^{-1}$, but over a period of a week this changes into a mixed valence charge transfer state with loss of iodine and an increase in conductivity to up to $10^{-5} \mathrm{~S} \mathrm{~cm}^{-1}$. Spectroscopic measurements support this interpretation with the initially formed material showing a band at $850 \mathrm{~nm}$ which slowly disappears over the week with the appearance of a band at $2300 \mathrm{~nm}$. This material showed semiconducting behavior in the 190-290 K range with an activation energy of $0.35 \mathrm{eV}$. Conductivity values though do not necessarily correspond to one single fiber. TCNQ doped material also shows a conductivity up to $1 \times 10^{-5} \mathrm{~S} \mathrm{~cm}^{-1}$. Fibrous aggregates have also been obtained from $\mathbf{7 2}$ in the homogeneously oriented smectic A phase of 73, with growth along the smectic layers. A few TTFs containing sugar residues have been prepared, including Alea's remarkable bis(TTF)-macrocycle $74 .^{47}$ 


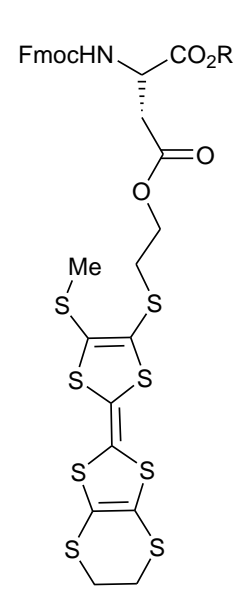

67

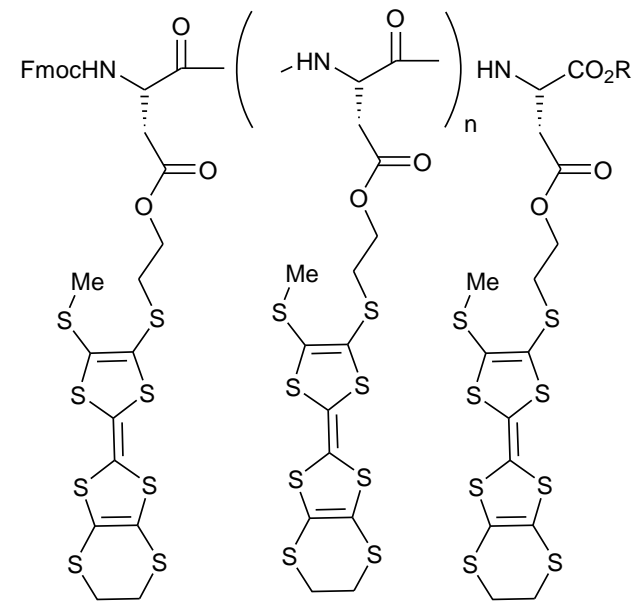

$68 \mathrm{n}=0$

$69 \mathrm{n}=1$
$70 \mathrm{n}=2$<smiles>CCCCCNC(=O)[C@H](CC(C)C)NC(=O)COCC1=CSC(=C2SC=CS2)S1</smiles><smiles>CCCCNC(=O)C(NC(=O)COCC1=CSC(=C2CC=CS2)S1)C(C)C</smiles>

72
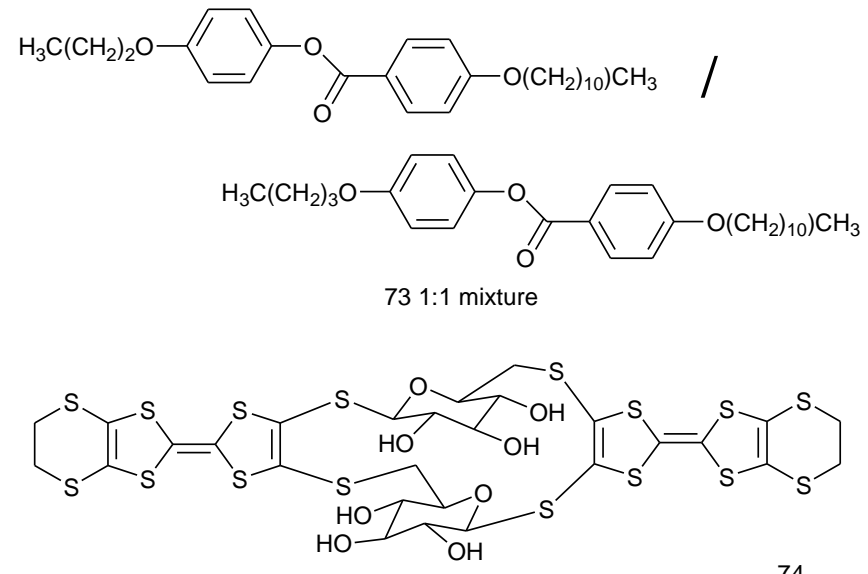

74

\subsection{Bis(pyrrolo)TTFs}

Becher introduced the bis(pyrrolo)TTF system which has the structural advantage of having one position at each end of the molecule for attachments, ${ }^{48}$ and which he has used in a wide variety of new TTF derivatives and supramolecular structures. ${ }^{49}$ More recently, derivatives have been prepared with chiral side chains attached to the nitrogen atoms. ${ }^{50}$ Thus, following 
Becher's general strategy, an enantiopure amine was reacted with the dibromide $\mathbf{7 5}$ to give the fused thione 76 which was then oxidized to the pyrrolo-1,3-dithiolane system 77 using DDQ (Scheme 14). Standard methods then yielded the enantiopure N,N'-disubstituted bis(pyrrolo)TTF ring system 79, in particular with (S)-1-phenylethyl or (R)-1-(1-naphthyl)ethyl sidechains 80 and $\mathbf{8 1}$. Some thiones of type $\mathbf{7 6}$ have also been elaborated into the corresponding donors containing dihydropyrrole rings 78. Of particular interest are the crystal structures of 80 and 81. The former is in the tetragonal space group $\mathrm{P} 4_{3} 2_{1} 2$, with just half of a donor crystallographically unique, such that the donors are arranged in chirally disposed layers perpendicular to the $c$ axis. (Fig 7). The latter approximates closely to this arrangement but in orthorhombic space group $\mathrm{C} 222_{1}$ with two half molecules in the asymmetric unit. This gives some encouragement to the eventual preparation of conducting materials where chirality is significantly expressed in the crystal structure.

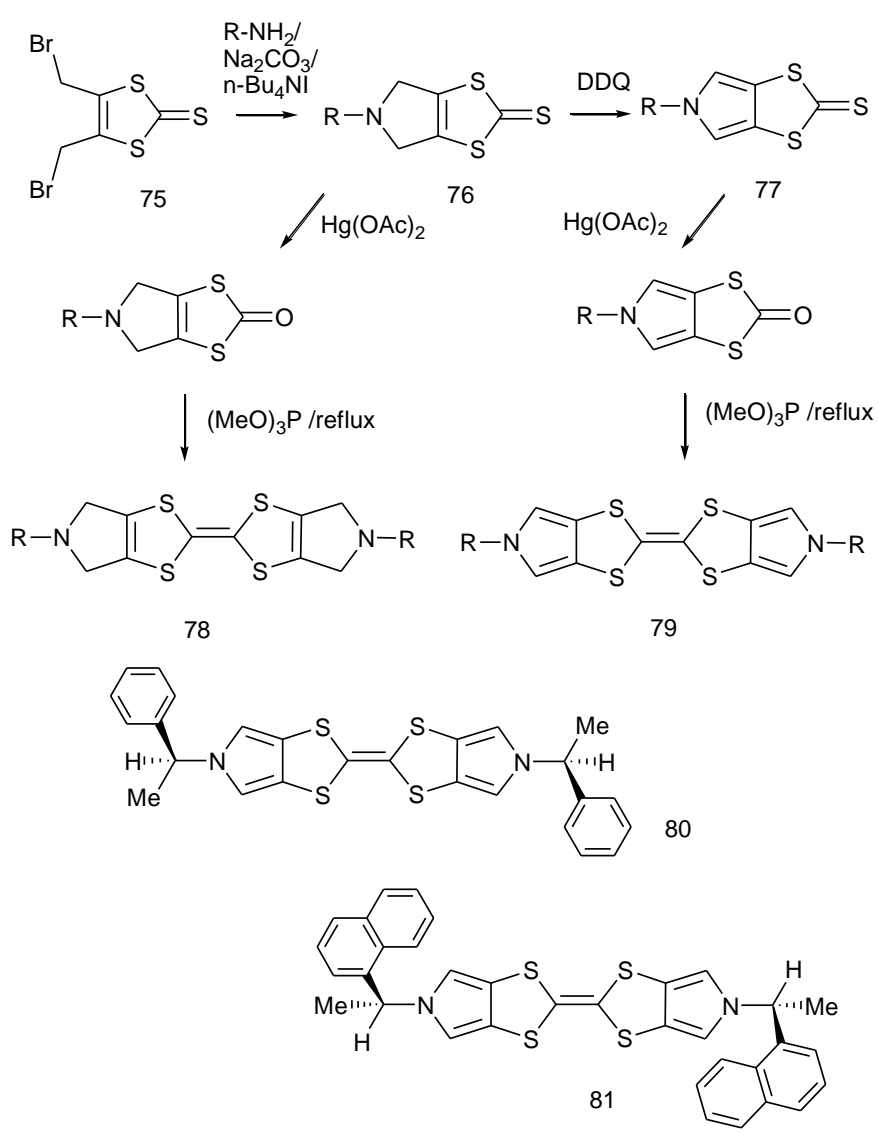

Scheme 14 Syntheses of bis(pyrrolo)TTFs and their tetrahydro derivatives. 


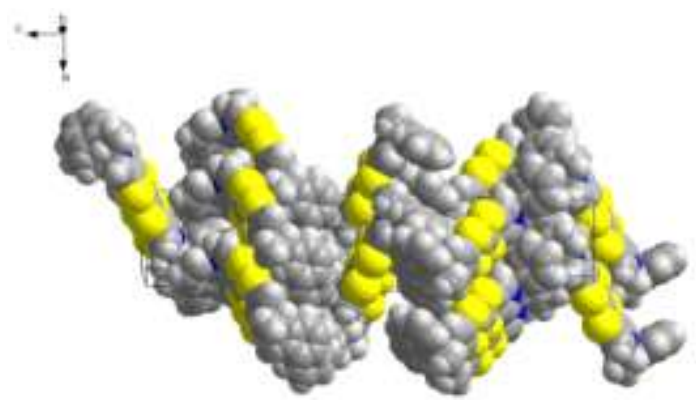

Fig. 7 Crystal packing of donor $\mathbf{8 0}$ with planes of donors related by a $4_{3}$ axis along $c$.

\section{Materials Derived from Chiral TTF donors}

\subsection{TTF-Oxazolines based conductors}

As discussed in the Section 2.3, a complete series of EDT-TTF-Me-oxazolines (47), consisting of the racemic and both enantiopure forms,${ }^{34}$ has been synthesized with the aim of converting these chiral precursors in radical cation salts. Accordingly, electrocrystallization of $(\mathrm{rac}),(R)$ or $(S)-47$ in solutions in methylene chloride in the presence of $\left[(n-\mathrm{Bu})_{4} \mathrm{~N}\right] \mathrm{AsF}_{6}$ as supporting electrolyte provided black crystalline needles which could be analyzed by single crystal X-ray diffraction. $^{51}$ This study demonstrated that the three compounds were mixed valence salts formulated as $\left[4_{7}\right]_{2} \mathrm{AsF}_{6}$. While the racemic salt crystallizes in the centrosymmetric space group $P-1$ of the triclinic system, with one independent molecule in the unit cell, both enantiopure salts crystallize in the corresponding non-centrosymmetric space group $P 1$, having the same cell parameters as the racemic counterpart. As a consequence there are two independent molecules in the unit cell, each corresponding to one of the possible planar conformations s-cis and s-trans, which are very likely the energy minima of the system. However, both conformations are also present in the structure of the racemic salt, but located this time on the same crystallographic site. This feature involves a structural disorder for the oxazoline ring refined at 0.5 , therefore both enantiomers $(S)$ (s-cis, dark gray) and $(R)(s$-trans, light gray) are equally present on the same crystallographic site (Fig. 8). 


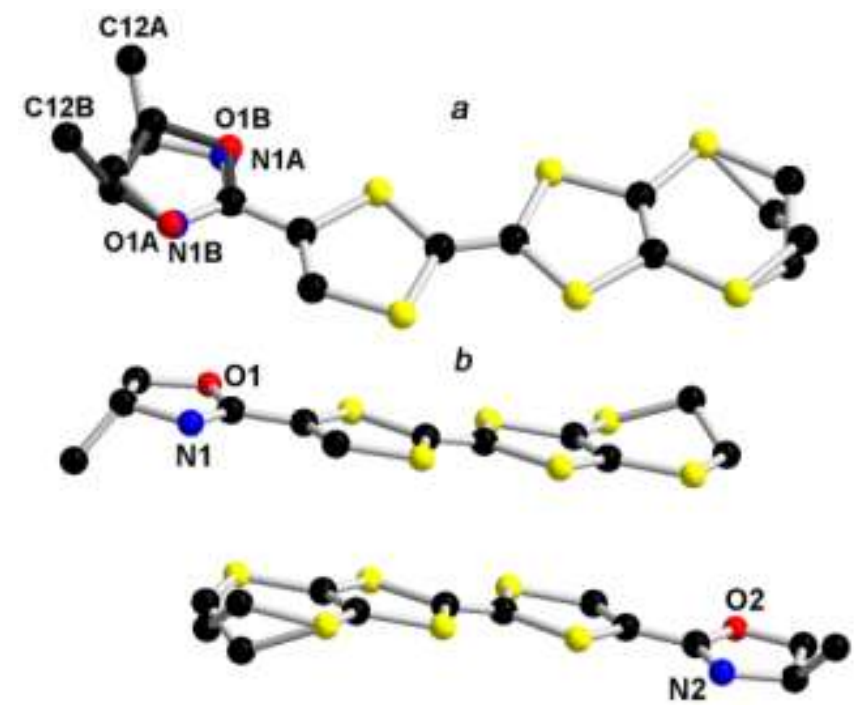

Fig. 8 Molecular structures of $[(\mathrm{rac})-47]_{2} \mathrm{AsF}_{6}$ (oxazoline in dark gray - enantiomer $S$, s.o.f 0.5; in light gray enantiomer $R$, s.o.f. 0.5) (a) and $[(R)-47]_{2} \mathrm{AsF}_{6}(\mathrm{~b})$. Hydrogen atoms have been omitted.

This observation is in line with the role of the chirality in the modulation of the structural disorder in the solid state, ${ }^{10}$ and hence the possible influence on the conducting properties of TTF based conductors. Indeed, this first complete series of mixed valence radical cation salts shows metallic behavior down to approximately $230 \mathrm{~K}$, followed by a localized regime, with, however, a room temperature conductivity which is one order of magnitude higher for the enantiopure salts $\left(\sigma_{\mathrm{RT}} \approx 100 \mathrm{~S} \mathrm{~cm}^{-1}\right)$ than for the racemic one $\left(\sigma_{\mathrm{RT}} \approx 10 \mathrm{~S} \mathrm{~cm}^{-1}\right)$ (Fig. 9).

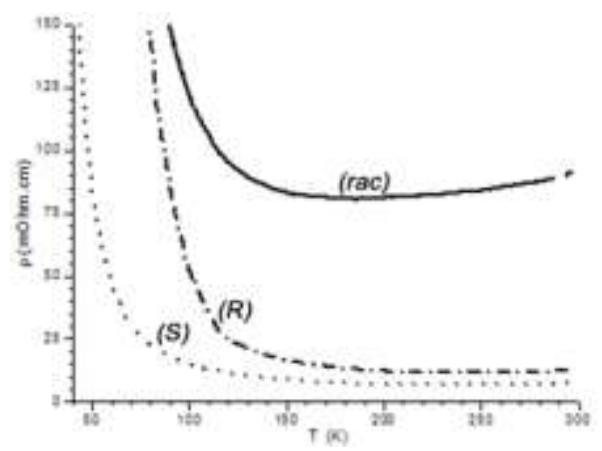

Fig. 9 Temperature dependence of the resistivity for $[47]_{2} \mathrm{AsF}_{6}(\mathrm{rac}),(R)$ and $(S)$.

The difference observed here is clearly related to the structural disorder mediated by the presence of the chiral group, since the three salts show identical band structures and open Fermi surfaces, together with similar $\beta$-type packings. In this respect, the synthesis of this first complete series of chiral molecular conductors represents an important achievement illustrating one of the possible roles of chirality in the field of molecular materials. It is expected that upon variation of the anion in radical cation salts and/or the substituent on the oxazoline ring more related complete series based on these chiral donors will be available for useful comparisons. 
Although not directly related to chirality issues, an interesting result has been obtained with the EDT-TTF-SMe-oxazoline donors $\mathbf{5 1}$ which provided in their racemic form a series of radical cation salts of different stoichiometries, i.e. $2: 1,4: 1$ and 6:1, with the same dianion $\left[\mathrm{Mo}_{6} \mathrm{Cl}_{14}\right]^{2-}$ only by changing the electrocrystallization solvent. ${ }^{38}$ The occurrence of short intramolecular $\mathrm{O} \cdots \mathrm{S}$ and $\mathrm{N} \cdots \mathrm{S}$ nonbonded interactions has been experimentally and theoretically evidenced.

\subsection{Methylated BEDT-TTF based conductors and superconductors}

Only the radical cation salts of enantiopure dimethyl and tetramethyl-BEDT-TTF 12 and $\mathbf{4}$ have been investigated in significant detail so far, though others are being studied currently. Dunitz, Hilti et al. prepared salts from $(S, S, S, S)-\mathbf{4}$, and isolated 2:1 salts when octahedral anions were used $\left(\mathrm{PF}_{6}{ }^{-}, \mathrm{AsF}_{6}{ }^{-}\right.$and $\left.\mathrm{SbF}_{6}{ }^{-}\right)$and salts with composition $\sim 3: 2$ isolated with tetrahedral anions $\left(\mathrm{BF}_{4}{ }^{-}\right.$and $\mathrm{ClO}_{4}{ }^{-}$) (Fig. 10). ${ }^{52}$ The structures within each group have similar cell parameters, and structural studies were made on $\mathrm{PF}_{6}^{-}, \mathrm{BF}_{4}^{-}$and $\mathrm{ClO}_{4}^{-}$salts. All four methyl groups adopt pseudo-equatorial positions on the dithiin rings which have approximate half-chair conformations. The crystal structures are all pseudo-centrosymmetric in $P 1$, with anion channels bounded by methyl groups between the stacks of donors. For the tetrahedral anions the channels are sufficiently wide for alternative locations of the anions, and the variation of electrical behaviour between individual crystals of the $\mathrm{ClO}_{4}$ salt may depend on the particular composition of the solvent included in this channel. Triiodide forms a salt with similar cell dimensions to the 2:1 salts, but with incommensurate rows of $\mathrm{I}_{3}^{-}$in the channels, and approximate composition donor: $\mathrm{I}_{3}$ of 2:0.71. The 2:1 salts show semiconducting behaviour, with highest conductivity along the stacking axis, and the triiodide salt is weakly metallic down to $230 \mathrm{~K}$, with a room temperature conductivity of $\sim 12 \mathrm{~S} \mathrm{~cm}^{-1}$. The behaviour of the $3: 2$ perchlorate salt has been investigated in some detail. The variation of conductivity with temperature depends on the solvent used in the electrocrystallisation, and up to $5 \%$ of solvent by weight has been detected in the crystals by techniques such as thermal gravimetry. Solvent could be located in the anion channels (or perhaps even in small holes in the crystals). Most interesting are crystals grown from 1,1,1-trichloroethane/nitrobenzene (1:1), some of which show a striking increase ( 3 orders of magnitude) in conductivity on cooling to $100 \mathrm{~K}$, while those grown from trichlorobenzene/nitrobenzene are semiconducting. There is certainly scope for further exploration for forming new radical cations salts from this donor, though chirality is not strongly expressed in the crystal structures of the salts prepared to date. 


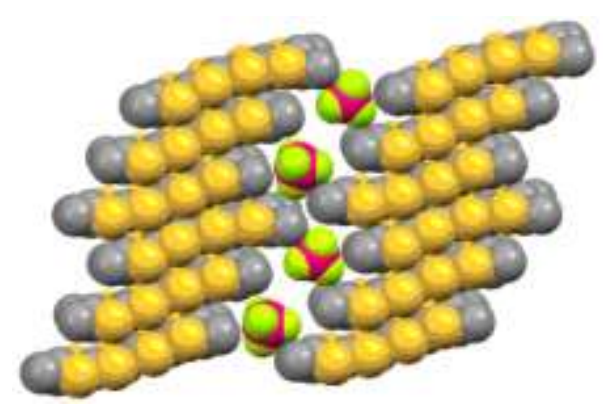

Fig 10 Crystal structure of $[(S, S, S, S)-4]_{3}\left(\mathrm{BF}_{4}\right)_{2}$ showing the channel occupied by the anions; $\mathrm{H}$ atoms are not shown.

A family of semiconducting 2:1 radical salts of enantiopure $(R, R)-\mathbf{1 2}$ with $\mathrm{PF}_{6}^{-}, \mathrm{ClO}_{4}^{-}$and $\mathrm{ReO}_{4}{ }^{-}$with very similar orthorhombic crystal structures (Fig. 11 for the $\mathrm{PF}_{6}{ }^{-}$salt) has been described by a Japanese group, along with the monoclinic structure of the $\mathrm{PF}_{6}{ }^{-}$salt of racemic donor (Fig. 12). ${ }^{53}$

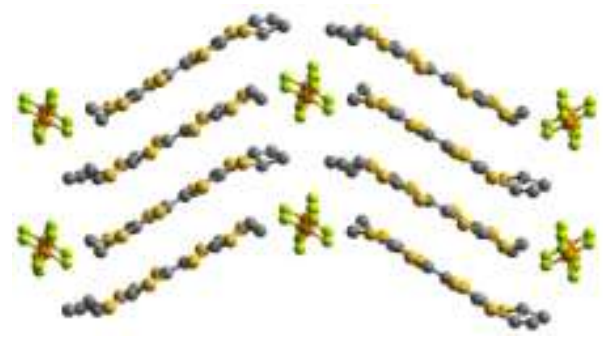

Fig 11 Crystal structure of $(R, R-\mathbf{1 2})_{2} \mathrm{PF}_{6}$ in space group $P 222_{l}$ viewed down the $b$ axis, with $c$ axis horizontal.

All these salts show head to tail stacking of donors, and the long axes of alternate donors are twisted at $c a .30^{\circ}$ to each other. The crystal packing of the racemic salt differs from the others in that neighbouring stacks are related by inversion symmetry rather than two fold symmetry, and the anion is only ordered in the racemic case where the cavity in which it lies is centrosymmetric.

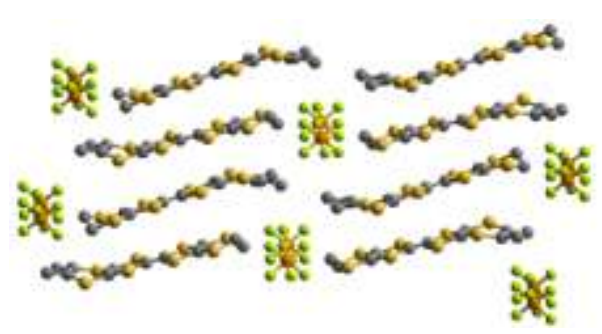

Fig 12 Crystal structure of racemic $(\mathbf{1 2})_{2} \mathrm{PF}_{6}$ in space group $P 2 / c$ viewed down the $b$ axis with $c$ axis horizontal.

In contrast, the achiral meso-dimethyl-BEDT-TTF forms a triclinic $2: 1 \mathrm{PF}_{6}^{-}$salt which becomes superconducting at $4.3 \mathrm{~K}$ under 4 kbar pressure. ${ }^{54}$ Nevertheless, the most interesting result for the chiral donor $(S, S)$-12 is that it also forms a remarkable kappa phase which on 
cooling to $2 \mathrm{~K}$ undergoes a transition to a probable superconducting state under $5 \mathrm{kbar}$ pressure. ${ }^{55}$ Some further salts with linear anions e.g. $\mathrm{I}_{3}^{-}$and $\left[\mathrm{Ag}(\mathrm{CN})_{2}\right]^{-}$which are semi-conducting, and $\mathrm{AuI}_{2}^{-}$which is metallic down to low temperatures have also been briefly reported. ${ }^{56}$

A family of salts of either $S, S-\mathbf{1 2}$ or the corresponding chiral pyrazine fused donor with linear anions $\mathrm{AuI}_{2}{ }^{-}, \mathrm{AuBr}_{2}{ }^{-}$or $\left[\mathrm{Ag}(\mathrm{CN})_{2}\right]^{-}$have been reported by Papavassilliou. ${ }^{57}$ They form metallic $\tau$-phases in tetragonal crystals (space group $\mathrm{I}_{4}{ }_{1} 22$ ) containing alternating layers of (a) donors and anions in 2:1 ratio and (b) disordered anions, approximating to the overall formula (donor) $)_{2}$ (anion) $)_{1.7}$. The complex electromagnetic properties of these materials have been extensively studied, and particular observations include large negative magnetoresistance and giant Shubnikov-de Haas oscillations. ${ }^{58}$ The precise distribution of donors between valence states $(0,+1$ and +2$)$ remains unclear. Some racemic forms have also been synthesized and form tetragonal crystals. The Nottingham Trent group is involved in preliminary attempts to prepare radical cation salts from other enantiopure donors such as $\mathbf{3 4}$ and $\mathbf{3 5}$ by electrocrystallisation, iodine diffusion or reaction with TCNQ. For example, donor $\mathbf{3 4}$ forms a triiodide salt in which the donors pack in pairs separated by the $\mathrm{I}_{3}$ ions (Fig. 13) and donor 35 forms a TCNQ salt with mixed stacks but with lines of donors oriented edge to edge perpendicular to the stacks. (Fig. 14). ${ }^{59}$

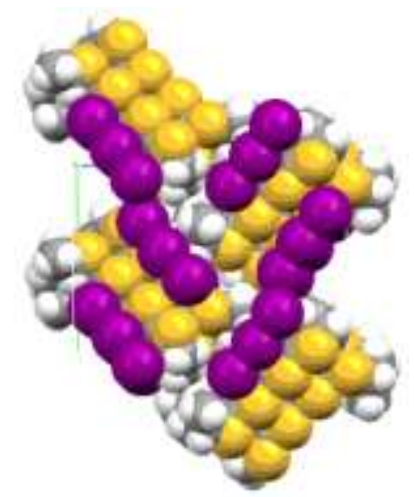

Fig. 13 Crystal packing of $\mathbf{3 4} . \mathrm{I}_{3}$ in space group $P 2_{1}$ with the $b$ axis lying vertical 


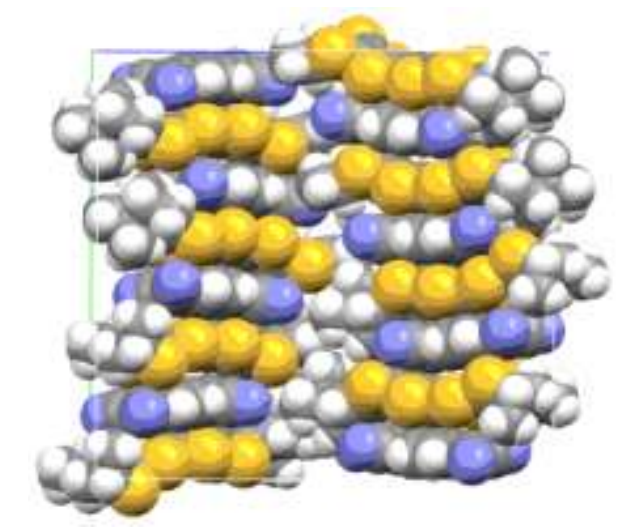

Fig. 14 Crystal packing of 35.TCNQ in space group $P 2_{1} 2_{1} 2_{1}$.

\section{Materials Derived from Chiral Anions and Achiral TTF donors}

An interesting alternative for preparing chiral molecular conductors consists of the use of chiral anions in radical cation salts of TTF derivatives which could in principle be chiral or not. However, only BEDT-TTF has been engaged so far in conducting salts with anions containing chiral centers, yet in only one published case has an enantiopure anion been used. This latter was the dianion $\left[\mathrm{Sb}_{2}(L \text {-tartrate })_{2}\right]^{2-}$ (Scheme 15$)$, which provided by electrocrystallization with BEDT-TTF a crystalline mixed valence salt, formulated as $[\text { BEDT-TTF }]_{3}\left[\mathrm{Sb}_{2}(\mathrm{~L}-\text { tartrate })_{2}\right] \cdot \mathrm{CH}_{3} \mathrm{CN}$, presenting semiconductor behaviour. ${ }^{60}$ Interestingly, circular dichroism measurements on both enantiomeric salts show rather strong Cotton effects in the UV-Visible region, a likely consequence of the overall chiral arrangement of the donors within the layer, imposed by the chirality of the anion.

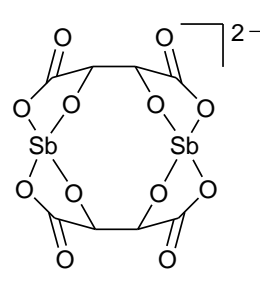

$\left[\mathrm{Sb}_{2}(\mathrm{~L}-\operatorname{tart})_{2}\right]^{2-}$<smiles>O=C(O)O[Te]12(OC(=O)OC(=O)O1)OC(=O)O2</smiles>

$\mathrm{M}=\stackrel{\left[\mathrm{M}(\mathrm{ox})_{3}\right]^{3-}}{\mathrm{Fe}^{3+}, \mathrm{Cr}^{3^{+}+}, \mathrm{Ga}^{3+}}$

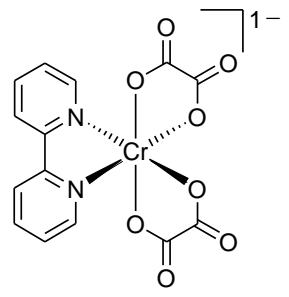

$\left[\mathrm{Cr}\left(2,2^{\prime}-\text { bipy }\right)(\mathrm{ox})_{2}\right]^{-}$<smiles></smiles>

TRISPHAT<smiles></smiles>

$\left[\mathrm{Fe}(\mathrm{Croc})_{3}\right]^{3-}$

Scheme 15 Examples of chiral anions used in radical cation salts with BEDT-TTF. 
More recent work deals with the preparation by Martin et al. of the first conducting salt containing a single enantiomer in the series $[\mathrm{BEDT}-\mathrm{TTF}]_{4}\left[(\mathrm{~A}) \mathrm{M}(\mathrm{ox})_{3}\right] \cdot$ guest (vide infra). The guest is nitromethane or dichloromethane, and the trisoxalate is present as only a single enantiomer. $^{61}$ In all the other examples reported so far, with anions such as $\left[\mathrm{M}(\mathrm{ox})_{3}\right]^{3-}(\mathrm{M}=$ $\left.\mathrm{Fe}^{3+}, \mathrm{Cr}^{3+}, \mathrm{Ga}^{3+}\right)$ in the extensive series of metals and superconductors formulated as $[\text { BEDT-TTF }]_{4}\left[(\mathrm{~A}) \mathrm{M}(\mathrm{ox})_{3}\right] \bullet \mathrm{S} \quad\left(\mathrm{A}=\mathrm{H}_{3} \mathrm{O}^{+}, \quad \mathrm{NH}_{4}{ }^{+} ; \mathrm{S}=\right.$ neutral guest molecule $){ }^{62}$ $\left[\mathrm{Cr}\left(2,2^{\prime} \text {-bipy }\right)(\mathrm{ox})_{2}\right]^{-}$in the semiconducting salt $[\mathrm{BEDT}-\mathrm{TTF}]_{2}\left[\mathrm{Cr}\left(2,2^{\prime}\right.\right.$-bipy $\left.)(\mathrm{ox})_{2}\right]{ }^{63}$ TRISPHAT in $1: 1$ insulating salts, ${ }^{64}$ or $\left[\mathrm{Fe}(\text { croconate })_{3}\right]^{3-}$ in the semiconducting salt $[\text { BEDT-TTF }]_{5}\left[\mathrm{Fe}(\mathrm{croc})_{3}\right] \cdot 5 \mathrm{H}_{2} \mathrm{O},{ }^{65}$ the anion was present in the crystal as a racemic mixture of $\Delta$ and $\Lambda$ enantiomers. Note however that the organization of $\Delta$ and $\Lambda$ enantiomers of the $\left[\mathrm{Cr}(\mathrm{Ox})_{3}\right]^{3-}$ anion was shown to influence the conductivity of polymorphs of the racemic salt $[\mathrm{BEDT}-\mathrm{TTF}]_{4}\left[\left(\mathrm{H}_{3} \mathrm{O}\right) \mathrm{Cr}(\mathrm{ox})_{3}\right] \cdot \mathrm{PhCN}^{6}{ }^{66}$ It would be therefore of great interest to access conducting salts based on enantiopure metal oxalates and related anions, all the more since they are also provided with magnetic properties, in which the donor could be also chiral. Worth mentioning is also the difference in conductivities which was observed in the conducting salts $[\text { BEDT-TTF }]_{4}\left[\left(\mathrm{NH}_{4}\right) \mathrm{Fe}(\mathrm{ox})_{3}\right]$ containing one molecule of either racemic or $(S)$-sec-phenethyl alcohol. ${ }^{67}$ The compounds present the same layered structure, consisting in alternated $\alpha$ and $\beta^{\prime \prime}$ type organic slabs (Fig. 15), separated by anion layers containing the guest ammonium cations and solvent molecules located in the resulting hexagonal cavities (Fig. 16). Within a layer all the anions have the same conformation, i.e. $\Delta$ or $\Lambda$, and thus each layer is homochiral.

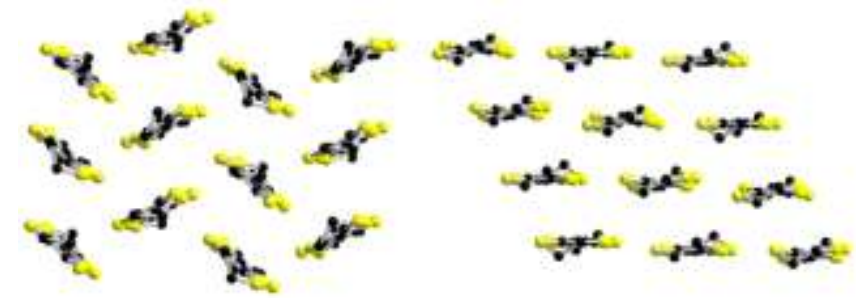

Fig. 15 View along the $b$ axis of $\alpha$ (left) and $\beta^{\prime \prime}$ (right) layers of BEDT-TTF in the structure of $[\mathrm{BEDT}-\mathrm{TTF}]_{4}\left[\left(\mathrm{NH}_{4}\right) \mathrm{Fe}(\mathrm{ox})_{3}\right] \cdot \mathrm{PhCH}(\mathrm{Me}) \mathrm{OH}$. $\mathrm{H}$ atoms have been omitted. 


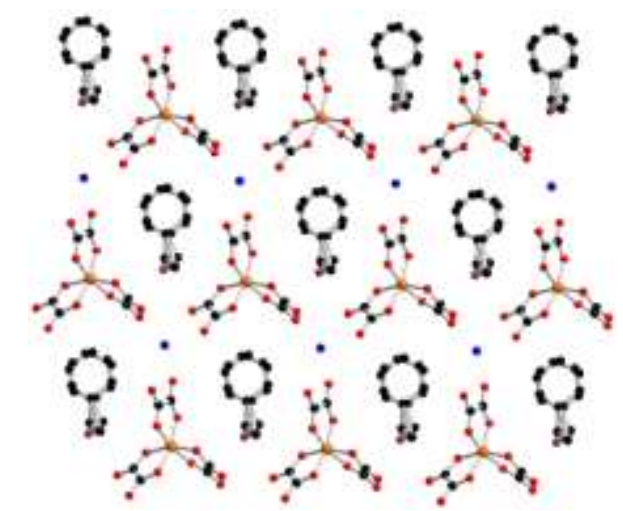

Fig. 16 Homochiral layer of tris(oxalate) showing the disordered ( $\mathrm{rac}$ )- $\mathrm{PhCH}(\mathrm{Me}) \mathrm{OH}$ solvent molecules. $\mathrm{H}$ atoms have been omitted.

The two salts have the same crystalline cell parameters excepting the space groups, which are triclinic $P-1$ for the one with the racemic solvent and triclinic $P l$ for that with the enantiopure solvent. As a consequence, in the latter there are two independent anions (for eight donor molecules) in the asymmetric unit, of $\Delta$ and $\Lambda$ conformations, while in the former there is only one independent anion (and four donor molecules), and thus the change of stereochemistry from one layer to the other occurs through the inversion centres. The only subtle structural difference between the two salts relies on the disorder observed in the one with the racemic solvent, for which both enantiomers statistically occupy the same crystallographic site (s.o.f. ratio refined at $58.5 \%: 41.5 \%$ ), while in the other only the $(S)$ enantiomer is present in the hexagonal cavity (Fig. 17).

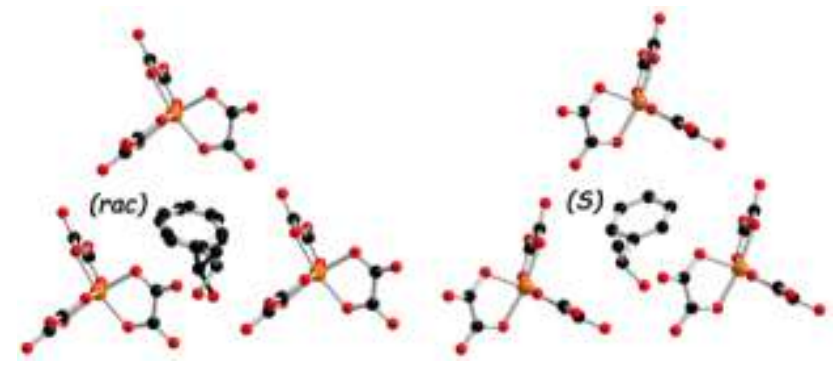

Fig. 17 Structural $(R / S)$ disorder (left) versus $(S)$ order (right) in $[\mathrm{BEDT}-\mathrm{TTF}]_{4}\left[\left(\mathrm{NH}_{4}\right) \mathrm{Fe}(\mathrm{ox})_{3}\right] \cdot \mathrm{PhCH}(\mathrm{Me}) \mathrm{OH}$.

As a consequence, a more pronounced metal-insulator transition was observed in the former, thus illustrating once again the role of the chirality in conductivity mediated by the structural disorder, as already evidenced previously in the salts based on TTF-oxazolines (vide supra).

\section{Supramolecular chirality}

\subsection{TTF mellitate salt}


Organizing organosulfur donors in a helix is an attractive supramolecular arrangement for investigating conductivity in a chiral system. Inabe electrocrystallised TTF with mellitic acid and pyridine to give a salt $\left[\mathrm{TTF}^{+}\right]_{2} \mathrm{C}_{6}\left(\mathrm{CO}_{2} \mathrm{H}\right)_{4}\left(\mathrm{CO}_{2}{ }^{-}\right)_{2}$ whose hexagonal crystal structure $\left(\mathrm{P}_{2} 22\right)$ contains a supramolecular arrangement of hydrogen bonded mellitate anions which forms a double helix around each column of TTF radical cations, with a period or repeat in the column after six TTF molecules. ${ }^{68}$ There is a crystallographic $6_{2}$ axis relating the molecules in the TTF stack, so there are two independent TTF molecules. One set of these does indeed obey the $6_{2}$ axis, and forms a helical arrangement. However, the other set is disordered between two positions, in which the donor is lying face to face with either the TTF below it or above it. Thus, most cation spins are paired. The magnetic properties suggest that $1-2 \%$ of the radical cations are unpaired, which could happen at domain boundaries along the stack. No conductivity measurements are reported. Nevertheless, this structure is quite instructive, since it highlights a problem in gaining a true helical arrangement of donors, that is the tendency to form pairs, which may persist even for a mixed valence stack. Much more control in the positions of the TTFs may be obtained if they are covalently linked to the external structures driving the formation of the helix.

\subsection{TTF-substituted poly(isocyanide)}

One interesting example of teleinduction of supramolecular chirality thanks to the presence of chiral TTF units has been recently reported by Amabilino et al. through the synthesis of an electroactive helical polymer (82) obtained by the polymerization of the isocyanide TTF derivative $\mathbf{8 1}$ containing two stereogenic centres (Scheme 16). ${ }^{69}$

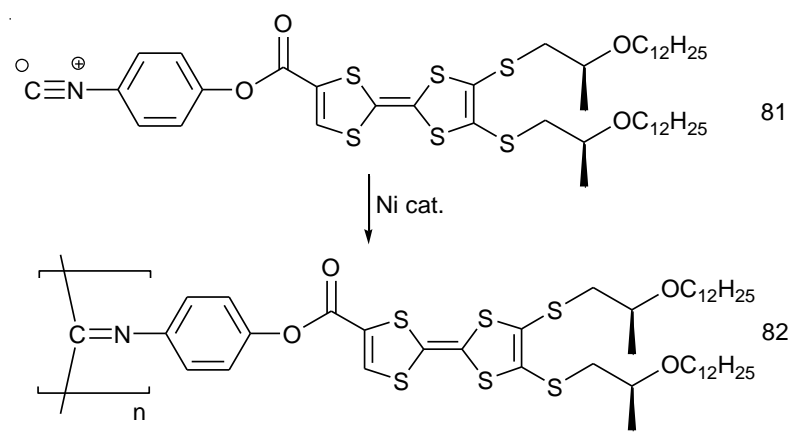

Scheme 16 Synthesis of poly(isocyanide) 82 with chiral TTFs.

It is assumed that the polymer adopts a helical conformation induced by the two chiral centers of the TTF unit, although they are located at about $18 \AA$ from the isocyanide group. This 
assumption is supported by the presence of a Cotton effect in CD spectrum of the polymer, arising from the $n-\pi^{*}$ transition of the imine group, and thus it is not observed in the CD spectrum of the monomer. Very interestingly, CD spectrum of the polymer shows reversible modulation depending on the oxidation state of the TTFs, corresponding to three univalent states (all TTFs $0,+1$ or +2 ) and two wide mixed valence states (variable proportions of TTFs 0 and +1 , or +1 and +2 ). It is therefore stated that this electroactive polymer can act as a multistate chiroptical redox switch. The presence of a broad charge-transfer absorption band centred at around $2000 \mathrm{~nm}$ in the spectrum of the partially oxidized polymer suggests significant intermolecular interactions between closely spaced TTFs, which could possibly allow for electron mobility along a helical pathway, a situation of much interest.

\subsection{Electroactive nanocoils from hexabenzocoronenes}

A major step forward in the search for chiral conducting molecular species came very recently with the production of chiral conducting nanocoils by Aida, Fukushima et al., ${ }^{70}$ an approach which may find application in the TTF area in the future. The nanocoils are prepared by diffusing diethyl ether into a dichloromethane solution containing two hexabenzocoronenes, $\mathbf{8 3}$ and $(S)-84$, in ratios of between 4:1 and 2:1. Only $\mathbf{8 4}$ has a stereogenic centre in the oligomeric polyether side chain, and this drives the assembly into a chiral left-handed nanocoil, in accord with the "sergeants-and-soldiers" principle. Nanocoils were identified in the precipitate formed by SEM microscopy. To stabilise the coiled structure with respect to a more stable nanotube structure, the norbornene groups are polymerized by ring opening metathesis polymerization. Right-handed nanocoils were produced under similar conditions but using $(R)-84$. The nanocoils were observed by SEM to have a diameter of $30 \mathrm{~nm}$, a pitch of $60 \mathrm{~nm}$ and tape width of $20 \mathrm{~nm}$. To investigate their electrical properties left-handed nanocoils were cast on to a pair of electrodes $5 \mu \mathrm{m}$ apart as a film and then doped with iodine vapour. The film showed conductivity of $1.4 \times 10^{-4} \mathrm{~S} \mathrm{~cm}^{-1}$, and similar values were found for the coils of either helicity prepared by choice of either enantiomer of $\mathbf{8 4}$. The nanocoils, with the polymerised surface, retained their structural integrity on doping. 


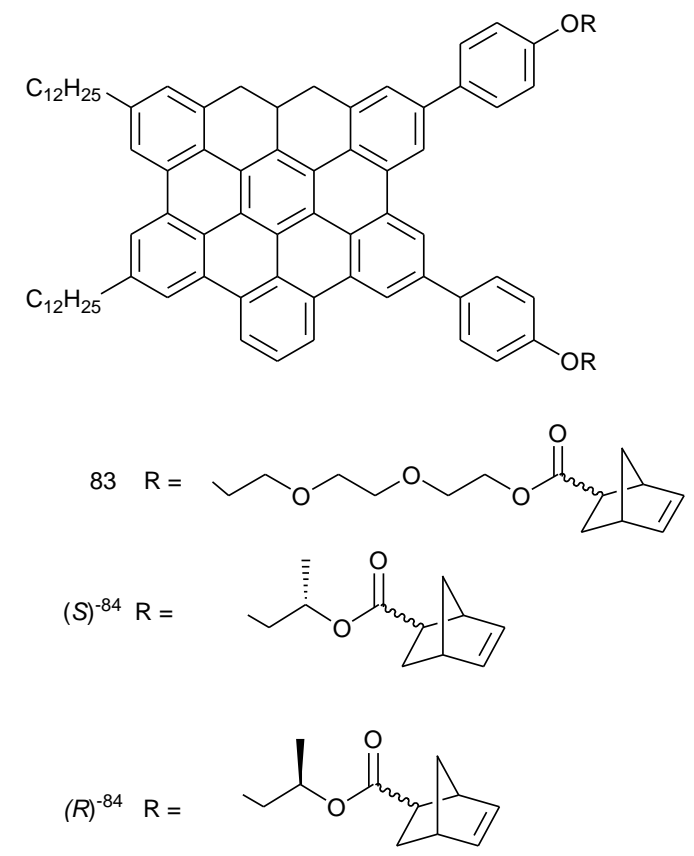

\section{Conclusions and outlook}

Finally, a range of enantiopure TTF based materials are now available, but to date not so many conducting materials have been prepared from them. There is thus much scope for further efforts in this area. As it was pointed out, a very important aspect relies on the preparation of families of chiral conductors containing both enantiomers but also the racemic form in order to compare their properties. In this respect, the first complete series of conducting mixed valence salts based on TTF-oxazolines, in which the conductivity of the racemate was one order of magnitude lower than that of the enantiopure forms, as a consequence of the structural disorder present in the former, is certainly a pertinent and promising case for further developments. Several conducting systems have been reported with chiral BEDT-TTF derivatives, but it is clear that, when considering the rich plethora of organic metals and superconductors based on BEDT-TTF, this direction is largely unexplored. The variation of the stereogenic centers, e.g. at carbon or sulfur atoms, and the type of chirality, e.g. point, axial, helical, is also an important aspect in view of the direct influence of the chirality on the conductivity through the electrical magneto-chiral anisotropy effect, for which experimental evidence in TTF series would represent a milestone. Since this effect has been observed so far in systems provided with helical chirality, the introduction of such type of chirality in TTF derivatives, through the synthesis of intrinsically helical molecules such as helicenes, ${ }^{71}$ the occurrence of chiral packings triggered by the presence of stereogenic centers, or the use of platforms which favor the supramolecular chirality, is of utmost interest. The last feature is related to the 
supramolecular organization of TTFs to provide electroactive assemblies such as gels, wires, fibers, ribbons, ${ }^{72}$ which could be envisaged as components for molecular electronic devices. ${ }^{73}$ Another interesting direction of investigation, arising from the combination of the two parallel strategies developed so far in the area of radical cation salts, e.g. use of chiral donors with achiral anions or achiral donors with chiral anions, would consist in the preparation of crystalline materials based on both chiral donors and anions, the latter possibly provided with magnetic properties, as multifunctional systems where magneto-chiral effects could be expressed at different levels. ${ }^{26}$

\section{Acknowledgments}

This work was supported by the CNRS, University of Angers and Nottingham Trent University. J.W. thanks the EPSRC for support (EP/C510488). Financial help from the COST Action D35 is also gratefully acknowledged. The authors thank all the coworkers appearing in the papers cited in the references.

\section{References}

1 (a) E. Coronado and P. Day, Chem. Rev., 2004, 104, 5419; (b) E. Coronado and J. R. Galán-Mascarós, J. Mater. Chem., 2005, 15, 66.

2 (a) V. Krstic, S. Roth, M. Burghard, K. Kern and G. L. J. A. Rikken, J. Chem. Phys., 2002, 117, 11315; (b) V. Krstic and G. L .J. A. Rikken, Chem. Phys. Lett., 2002, 364, 51.

3 G. L. J. A. Rikken, J. Folling and P. Wyder, Phys. Rev. Lett., 2001, 87, 236602.

4 (a) J. T. Chalker and S. L. Sondhi, Phys. Rev. B, 1999, 59, 4999; (b) A. Kleiner, Phys. Rev. B, 2003, 67, 155311; (c) R. Roy and C. Kallin, Phys. Rev. B, 2008, 77, 174513.

5 (a) G.-L. Yuan and N. Kuramoto, Macromolecules, 2003, 36, 7939; (b) D. Cornelis, H. Peeters, S. Zrig, B. Andrioletti, E. Rose, T. Verbiest, G. Koeckelberghs, Chem. Mater., 2008, 20, 2133.

6 (a) J. M. Williams, J. R. Ferraro, R. J. Thorn, K. D. Carlson, U. Geiser, H. H. Wang, A. M. Kini and M.-H. Whangbo, in Organic Superconductors (Including Fullerenes), Synthesis, Structure, Properties and Theory, R. N. Grimes, ed., Prentice-Hall, Englewoods Cliffs, NJ, 1992; (b) T. Ishiguro, K. Yamaji and G. Saito, Organic Superconductors, Heidelberg, Springer-Verlag, 1998. 
7 (a) J. L. Segura and N. Martin, Angew. Chem. Int. Ed., 2001, 40, 1372; (b) J.-I. Yamada, TTF Chemistry: Fundamentals and Applications of Tetrathiafulvalene, Springer-Verlag, Berlin and Heidelberg, 2004.

8 J. D. Dunitz, A. Karrer and J. D. Wallis, Helv. Chim. Acta, 1986, 69, 69.

9 J. D. Wallis and J.-P. Griffiths, J. Mater. Chem., 2005, 15, 347.

10 (a) H.-B. Bürgi and J. D. Dunitz, Helv. Chim. Acta, 1993, 76, 1115; (b) H. D. Flack, Helv. Chim. Acta, 2003, 86, 905; (c) H. D. Flack and G. Bernardinelli, Cryst. Eng. 2003, 6, 213; (d) R. Tamura, H. Takahashi, K. Hirotsu, Y. Nakajima, T. Ushio and F. Toda, Angew. Chem. Int. Ed., 1998, 37, 2876.

11 (a) G. Grüner, Rev. Mod. Phys., 1988, 60, 1129; (b) D. Jérome and H. J. Schulz, Adv. Phys., 1982, 31, 299.

12 A. Rajca, S. Rajca, M. Pink and M. Miyasaka, Synlett, 2007, 12, 1799.

13 A. P. H. J. Schenning, A. F. M. Kilbinger, F. Biscarini, M. Cavallini, H. J. Cooper, P. J. Derrick, W. J. Feast, R. Lazzaroni, P. Leclere, L. A. McDonell, E. W. Meijer, S. C. J. Meskers, J. Am. Chem. Soc., 2002, 124, 1269.

14 (a) W. Li and H.-L. Wang, J. Am. Chem. Soc., 2004, 126, 2278; (b) H. Goto, J. Polym. Sci., Part A: Polym. Chem., 2007, 45, 2085.

15 (a) D. Pijper and B. L. Feringa, Soft Matter, 2008, 4, 1349; (b) A. R. A. Palmans and E. W. Meijer, Angew. Chem. Int. Ed., 2007, 46, 8948; (c) S. J. George, Ž. Tomović, M. M. J. Smulders, T. F. A. de Greef, P. E. L. G. Leclère, E. W. Meijer and A. P. H. J. Schenning, Angew. Chem. Int. Ed., 2007, 46, 8206.

16 N. Saygili, R. J. Brown, R. Hoelzl, T. Ozturk, M. Pilkington, L. Vorwerg, J. D. Wallis, M. Qayyum, P. Kathirgamanathan, P. Day and S.S. Turner, Tetrahedron, 2001, 57, 5015.

17 F. Leurquin, T. Ozturk, M. Pilkington and J. D. Wallis, J. Chem. Soc., Perkin Trans 1, 1997 , 3173.

18 J.-P. Griffiths, N. Hui, R. J. Brown, P. Day and J. D. Wallis, Org. Biomol. Chem., 2005, 3, 2155.

19 T. Konoike, K. Namba, T. Shinada, K. Sakaguchi, G. C. Papavassiliou, K. Murata and Y. Ohfune, Synlett, 2001, 1476.

20 T. Ozturk, N. Saygili, S. Oskara, M. Pilkington, C. R. Rice, D. A. Tranter, F. Turksoy and J. D. Wallis, J. Chem. Soc., Perkin Trans. 1, 2001, 407.

21 T. Ozturk, C. R. Rice and J. D. Wallis, J. Mater. Chem., 1995, 5, 1553.

22 (a) J. S. Zambounis and C. W. Mayer, Tetrahedron Lett., 1991, 32, 2737; (b) C. W. Mayer and J. S. Zambounis, Eur. Pat. Appl., 1991, 90-810497. 
23 R. J. Brown, A. C. Brooks, J.-P. Griffiths, B. Vital, P. Day and J. D. Wallis, Org. Biomol. Chem., 2007, 5, 3172.

24 S. Yang, A. C. Brooks, P. Day, M. Pilkington and J. D. Wallis, in preparation.

25 G. A. Horley, T. Ozturk, F. Turksoy and J. D. Wallis, J. Chem. Soc., Perkin Trans 1, 1998, 3225.

26 C. Train, R. Gheorghe, V. Krstic, L.-M. Chamoreau, N. S. Ovanesyan, G. L. J. A. Rikken, M. Gruselle and M. Verdaguer, Nature Mater., 2008, 7, 729.

27 M. Chas, M. Lemarié, M. Gulea and N. Avarvari, Chem. Commun., 2008, 220.

28 M. V. Lakshmikantham, A. F. Garito and M. P. Cava, J. Org. Chem., 1978, 43, 4394.

29 L. Carlsen, K. Bechgaard, C. S. Jacobsen and I. Johansen, J. Chem. Soc., Perkin Trans. II, $1979,862$.

30 (a) F. A. Davis, R. T. Reddy, W. Han and P. J. Carroll, J. Am. Chem. Soc., 1992, 114, 1428;

(b) F. A. Davis and B. C. Chen, Chem. Rev., 1992, 92, 919.

31 I. Fernández and N. Khiar, Chem. Rev., 2003, 103, 3651.

32 M. Chas, F. Riobé, R. Sancho, C. Minguíllon and N. Avarvari, Chirality, 2009, accepted.

33 A. Chesney and M. R. Bryce, Tetrahedron: Asymmetry, 1996, 7, 3247.

34 C. Réthoré, M. Fourmigué and N. Avarvari, Chem. Commun., 2004, 1384.

35 C. Réthoré, M. Fourmigué and N. Avarvari, Tetrahedron, 2005, 61, 10935.

36 C. Réthoré, I. Suisse, F. Agbossou-Niedercorn, E. Guillamón, R. Llusar, M. Fourmigué and N. Avarvari, Tetrahedron, 2006, 62, 11942.

37 C. Réthoré, F. Riobé, M. Fourmigué, N. Avarvari, I. Suisse and F. Agbossou-Niedercorn, Tetrahedron: Asymmetry, 2007, 18, 1877.

38 C. Réthoré, A. Madalan, M. Fourmigué, E. Canadell, E. B. Lopes, M. Almeida, R. Clérac and N. Avarvari, New J. Chem., 2007, 31, 1468.

39 R. F. W. Bader, Chem. Rev., 1991, 91, 893.

40 A. M. Madalan, C. Réthoré and N. Avarvari, Inorg. Chim. Acta, 2007, 360, 233.

41 (a) R. Gómez, J. L. Segura and N. Martin, Org. Lett., 2000, 2, 1585; (b) R. Gómez, J. L. Segura and N. Martin, J. Org. Chem., 2000, 65, 7566.

42 Y. Zhou, D. Zhang, L. Zhu, Z. Shuai and D. Zhu, J. Org. Chem., 2006, 71, 2123.

43 E. Gomar-Nadal, C. Rovira and D. B. Amabilino, Tetrahedron, 2006, 62, 3370.

44 S. Yang, A. C. Brooks and J. D. Wallis, recent work.

45 S. Booth, E. N. K. Wallace, K. Singhal, P. N. Bartlett and J. D. Kilburn, J. Chem. Soc., Perkin Trans 1, 1998, 1467. 
46 T. Kitamura, S. Nakaso, N. Mizoshita, Y. Tochigi, T. Shimomura, M. Moriyama, K. Ito and T. Kato, J. Am. Chem. Soc., 2005, 127, 14769.

47 G. V. Alea, G. C. Janairo and J. D. Kilburn, Philipp. J. Sci., 2007, 136, 33.

48 (a) J. O. Jeppesen, K. Takimiya, F. Jensen, T. Brimert, K. Nielsen, N. Thorup and J. Becher, J. Org. Chem., 2000, 65, 5794; (b) J. Jeppesen, K. Takimiya, F. Jensen and J. Becher, Org. Lett., 1999, 1, 1291.

49 (a) M. B. Nielson, C. Lomholt and J. Becher, Chem. Soc. Rev., 2000, 29, 153; (b) J. Becher, J. O. Jeppersen and K. Nielsen, Synth. Met., 2003, 133-134, 309.

50 S. Yang, A. C Brooks, L. Martin, P. Day. L. Male, P. Horton and J. D. Wallis, article submitted.

51 C. Réthoré, N. Avarvari, E. Canadell, P. Auban-Senzier and M. Fourmigué, J. Am. Chem. Soc., 2005, 127, 5748.

52 A. Karrer, J. D. Wallis, J. D. Dunitz, B. Hilti, C. W. Mayer, M. Bürkle and J. Pfeiffer, Helv. Chim. Acta, 1987, 70, 942.

53 S. Matsumiya, A. Izuoka, T. Sugawara, T. Taruishi, Y. Kawada and M. Tokumoto, Bull. Chem. Soc. Jpn., 1993, 66, 1949.

54 (a) S. Kimura, T. Maejima, H. Suzuki, R. Chiba, H. Mori, T. Kawamoto, T. Mori, H. Moriyama, Y. Nishio and K. Kajita, Chem. Commun., 2004, 2454; (b) S. Kimura, H. Suzuki, T. Maejima, H. Mori, J.-I. Yamaura, T. Kakiuchi, H. Sawa and H. Moriyama, J. Am. Chem. Soc., 2006, 128, 1456.

55 J. S. Zambounis, C. W. Mayer, K. Hauenstein, B. Hilti, W. Hofherr, J. Pfeiffer, M. Buerkle and G. Rihs, Adv. Mater., 1992, 4, 33.

56 J. S. Zambounis, C. W. Mayer, K. Hauenstein, B. Hilti, W. Hofherr, J. Pfeiffer, M. Buerkle and G. Rihs, Mat. Res. Soc. Symp. Proc., 1992, 247, 509.

57 G. C. Papavassiliou, G. A. Mousdis, A. Terzis, C. Raptopoulou, K. Murata, T. Konoike and Y.Yoshino, Synth. Met., 2001, 120, 743.

58 (a) T. Nakanishi, L. Li, H. Yoshino, S. Yasazuka, D. Graf, E. S. Choi, J. S. Brooks, G. C. Papavassiliou and K. Murata, Synth. Met., 2005, 152, 425; (b) K. Murata, T. Konoike, K. Iwashita, H. Yoshino, T. Sasaki, K. Hiraki, T. Takahashi, Y. Nishio, K. Kajita and G. C. Papavassiliou, Synth. Met., 2003, 133-134, 103; (c) K. Hiraki, T. Takahashi, T. Konoike, H. Yoshino, K. Murata and G. C. Papavassiliou, Synth. Met., 2003, 133-134, 159; (d) H. Yoshino, K. Murata, T. Sasaki, K. Iimura, A. Oda and G. C. Papavassiliou, Synth. Met., 1999, 103, 2010; (e) G. C. Papavassiliou, D. J. Lagouvardos, A. Terzis, C. P. Raptopoulou, 
B. Hilti, W. Hofherr, J. S. Zambounis, G. Rihs, J. Pfeiffer, P. Delhaes, K. Murata, N. A. Fortune and N. Shirakawa, Synth. Met., 1995, 70, 787.

59 S. Yang, A. C. Brooks, P. Day and J. D. Wallis, in preparation.

60 E. Coronado, J. R. Galán-Mascarós, C. J. Gómez-Garcia, A. Murcia-Martinez and E. Canadell, Inorg. Chem., 2004, 43, 8072.

61 L. Martin, P. Day, S-i. Nakatsuji, J-i. Yamada and H. Akutsu, in preparation.

62 (a) E. Coronado and P. Day, Chem. Rev., 2004, 104, 5419; (b) E. Coronado and J. R. Galán-Mascarós, J. Mater. Chem., 2005, 15, 66; (c) P. Day and M. Kurmoo, J. Mater. Chem., 1997, 7, 1291.

63 A. M. Madalan, E. Canadell, P. Auban-Senzier, D. Brânzea, N. Avarvari and M. Andruh, New J. Chem., 2008, 32, 333.

64 M. Clemente-León, E. Coronado, C. J. Gómez-García, A. Soriano-Portillo, S. Constant, R. Frantz, J. Lacour, Inorg. Chim. Acta, 2007, 360, 955.

65 C. J. Gómez-García, E. Coronado, S. Curreli, Carlos Giménez-Saiz, P. Deplano, M. L. Mercuri, L. Pilia, A. Serpe, C. Faulmann and E. Canadell, Chem. Commun., 2006, 4931.

66 L. Martin, S. S. Turner, P. Day, K. M. Abdul Malik, S. J. Coles, M. B. Hursthouse, Chem. Commun., 1999, 513.

67 L. Martin, P. Day, H. Akutsu, J. Yamada, S. Nakatsuji, W. Clegg, R. W. Harrington, P. N. Horton, M. B. Hursthouse, P. McMillan and S. Firth, CrystEngComm., 2007, 9, 865.

68 N. Kobayashi, T. Naito and T. Inabe, Adv. Mater., 2004, 16, 1803.

69 E. Gomar-Nadal, J. Veciana, C. Rovira and D. B. Amabilino, Adv. Mater., 2005, 17, 2095.

70 T. Yamamoto, T. Fukushima, A. Kosaka, W. Jin, Y. Yamamoto, N. Ishii and T. Aida, Angew. Chem. Int. Ed., 2008, 47, 1672.

71 C. Nuckolls, T. J. Katz, G. Katz, P. J. Collings and L. Castellanos, J. Am. Chem. Soc., 1999, 121, 79 .

72 (a) M. Iyoda M. Hasegawa and H. Enozawa, Chem. Lett., 2007, 36, 1402; (b) E. Gomar-Nadal, J. Puigmartí-Luis and D.B. Amabilino, Chem. Soc. Rev., 2008, 37, 490 (c) I. Danila, F. Riobé, J. Puigmartí-Luis, Á. Pérez del Pino, J. D. Wallis, D. B. Amabilino and N. Avarvari, submitted.

73 A. P. H. J. Schenning and E. W. Meijer, Chem. Commun., 2005, 3245. 